\title{
microRNA-21 Regulates Astrocytic Response Following Spinal Cord Injury
}

\author{
Oneil G. Bhalala, ${ }^{1}$ Liuliu Pan, ${ }^{1}$ Vibhu Sahni, ${ }^{1}$ Tammy L. McGuire, ${ }^{1}$ Katherine Gruner, ${ }^{2}$ Warren G. Tourtellotte, ${ }^{1,2}$ \\ and John A. Kessler ${ }^{1}$ \\ Departments of ${ }^{1}$ Neurology and 2 Pathology, Feinberg School of Medicine, Northwestern University, Chicago, Illinois 60611
}

Astrogliosis following spinal cord injury (SCI) involves an early hypertrophic response that serves to repair damaged blood-brain barrier and a subsequent hyperplastic response that results in a dense scar that impedes axon regeneration. The mechanisms regulating these two phases of astrogliosis are beginning to be elucidated. In this study, we found that microRNA-21 (miR-21) increases in a timedependent manner following SCI in mouse. Astrocytes adjacent to the lesion area express high levels of miR-21 whereas astrocytes in uninjured spinal cord express low levels of miR-21. To study the role of miR-21 in astrocytes after SCI, transgenic mice were generated that conditionally overexpress either the primary miR-21 transcript in astrocytes or a miRNA sponge designed to inhibit miR-21 function. Overexpression of miR-21 in astrocytes attenuated the hypertrophic response to SCI. Conversely, expression of the miR-21 sponge augmented the hypertrophic phenotype, even in chronic stages of SCI recovery when astrocytes have normally become smaller in size with fine processes. Inhibition of miR-21 function in astrocytes also resulted in increased axon density within the lesion site. These findings demonstrate a novel role for miR-21 in regulating astrocytic hypertrophy and glial scar progression after SCI, and suggest miR-21 as a potential therapeutic target for manipulating gliosis and enhancing functional outcome.

\section{Introduction}

Astrocytes play a critical role after SCI where their response consists of an initial hypertrophy followed by hyperplasia (Fawcett and Asher, 1999; Barnabé-Heider and Frisén, 2008; Sahni et al., 2010). During the hypertrophic phase, astrocytes become reactive and exhibit enlarged somata as well as thick processes and increased expression of the intermediate filament proteins glial fibrillary acidic protein (GFAP) and vimentin (Pekny and Pekna, 2004). These morphological changes provide a beneficial effect by facilitating repair of the blood-brain barrier while limiting spread of inflammatory cells (Faulkner et al., 2004; Sofroniew, 2005; Okada et al., 2006; Herrmann et al., 2008). Contrastingly, during the hyperplastic response, astrocytes increase in number around the injury site and display much finer processes, contributing to progression of the glial scar. This glial scar has been shown to be a significant barrier for axonal regeneration (Fawcett and Asher, 1999; Silver and Miller, 2004).

\footnotetext{
Received Aug. 13, 2012; revised Sept. 13, 2012; accepted 0ct. 12, 2012.

Author contributions: 0.G.B., V.S., W.G.T., and J.A.K. designed research; 0.G.B., L.P., T.L.M., and K.G. performed research; 0.G.B. and J.A.K. analyzed data; 0.G.B., W.G.T., and J.A.K. wrote the paper.

This project was supported by National Institutes of Health Grants R01 NS 20013 and R01 NS 20778. We thank Anjen Chenn (University of Illinois at Chicago) and Jessica D. Schulte (Northwestern University) for their help with the MSP luciferase assays, the Northwestern University Transgenic and Targeted Mutagenesis Core for their assistance with generating ROSA-miR21 and ROSA-MSP mice, and Deeti Bhalala for her critical reading of this manuscript.

The authors declare no competing financial interests.

Correspondence should be addressed to Oneil G. Bhalala, 303 East Chicago Avenue, Ward 10-233, Chicago, IL 60611. E-mail: oneil-bhalala@fsm.northwestern.edu.

V. Sahni's present address: Department of Stem Cell and Regenerative Biology, Harvard University, Cambridge, MA 02138.

DOI:10.1523/JNEUROSCI.3860-12.2012

Copyright $\odot 2012$ the authors $\quad 0270-6474 / 12 / 3217935-13 \$ 15.00 / 0$
}

MicroRNAs (miRNAs) are post-transcriptional regulators of gene expression (Bartel, 2004). The primary miRNA (primiRNA) is transcribed from the genome by RNA polymerase II and processed by Drosha, yielding the precursor miRNA transcript (Carthew and Sontheimer, 2009). This precursor miRNA (pre-miRNA) is exported into the cytoplasm and processed by Dicer-containing enzyme complex to produce a noncoding 20-24 nucleotide mature miRNA. Mature miRNAs bind to complementary sequences on target messenger RNA transcripts (mRNAs), resulting in gene silencing through target mRNA degradation and/or translational repression. miRNAs regulate a diverse set of functions under homeostatic as well as pathological conditions (Qureshi and Mehler, 2012). Many miRNAs are altered following SCI (Liu et al., 2009; Liu et al., 2010; Yunta et al., 2012) including miR-21. Interestingly, miR-21 expression and processing is regulated by bone morphogenetic protein (BMP) and JAK-STAT signaling pathways, which have been shown to critically regulate the astrocytic responses after SCI (Setoguchi et al., 2004; Enzmann et al., 2005; Davis et al., 2008; Matsuura et al., 2008; Sahni et al., 2010; Ahmed et al., 2011; Kohanbash and Okada, 2012). We have also previously shown that overexpression of miR-21 in cultured astrocytes causes a decrease in cell size, process thickness, and GFAP expression (Sahni et al., 2010). These observations suggest a potential role for miR-21 in regulating astrogliosis after SCI.

Here, we investigated the role of miR-21 in astrocytic responses after severe SCI in vivo. We found that miR-21 expression increases in astrocytes adjacent to the lesion site. Conditional overexpression of miR-21 in astrocytes reduced astrocytic hypertrophy after SCI. In contrast, inhibiting miR-21 using miRNA sponge technology not only augmented the hypertrophic response but also increased the 
number of axons within the lesion at chronic stages of injury. These data suggest that miR-21 can be targeted therapeutically to enhance astrocytic hypertrophy and modulate progression of the glial scar to potentially increase functional recovery after SCI.

\section{Materials and Methods}

Generation of ROSA-miR21 and ROSA-MSP mice. Transgenic ROSA-miR21 mice were generated by inserting 381 base pairs of the murine primary miR-21 transcript (Ensembl Genome, mouse chromosome 11 base pairs 86,397,432$86,397,811$, negative strand) into the XhoI and NotI sites of pCAG-BigT. pCAG-BigT was generated from pBigT (Srinivas et al., 2001) by inserting the CAG (CMV-chicken $\beta$-actin) promoter amplified from pCAGGS-Flpe plasmid (Schaft et al., 2001) upstream of the loxstop-lox cassette in $\mathrm{pBigT}$. The precursor stem loop of miR-21 is made up of base pairs $86,397,569-660$ and the mature sequence consists of base pairs 86,397,622-643. The pCAGBigT-ROSA-miR21 construct was inserted into PacI and AscI sites into pROSA26-PA to generate the final targeting vector. The targeting vector was linearized with $\mathrm{KpnI}$ and electroporated into C57BL/6 ES cells. ES cells were selected for neomycin (PGK-Neo) expression using G418 and negative selection was performed via a diphtheria toxin-A (DT-A) cassette in $3^{\prime}$ end of the targeting vector. Homologous recombinants were screened by Southern blot using probes for $5^{\prime}$ and $3^{\prime}$ sites that were external to the vector recombination arms. To validate the performance of the targeting construct, targeted ES cells were infected with either adenovirus encoding for GFP (AdGFP) or Cre-recombinase protein (Ad-Cre), and RNA was extracted using RNAqueousMicro Kit (Ambion) per manufacturer's protocol. Recombinant clones with the highest transgene expression were selected for injection into C57BL/ 6 blastocysts. Male chimeras were mated with C57BL/6 females to establish three independent lines. These lines were found to be similar so only a single line was propagated and further analyzed. DNA was isolated from tail biopsies and genotyping was performed by PCR with the following primers: miR21 forward, ATGGCTGTACCACCTTGTCGGATA and miR21 reverse, AGCATGCCTGCTATTGTCTTCCCA for transgene presence.

Transgenic ROSA-miR21 sponge (ROSA-MSP) mice were generated by inserting the seven miR-21 sponge repeat and bovine growth hormone polyadenylation termination sequences from pCMV-d2eGFPmiR21 (Ebert et al., 2007) into the XhoI and NotI sites of pCAG-BigT. Generation and validation of ROSA-MSP chimeras was performed as described above for ROSA-miR21 mice. Genotyping primers specific for MSP (MSP forward, GCTCTATGGCTTCTGAGC; MSP reverse, CGAAAATCTGTGGGAAGTCTTG) were used to detect germ line transmission by PCR from chimeras and subsequent generations.

Transgenic mouse lines. The ROSA-miR21 and ROSA-MSP lines were maintained in a C57BL/6 background and were crossed to a GFAP-Cre mouse line (73.12, generously provided by Dr. Michael Sofroniew, University of California Los Angeles, Los Angeles, CA). Generation and genotyping of the GFAP-Cre line has been described previously (Garcia et al., 2004). Genotyping of offspring was performed as described above for ROSA-miR21 and ROSA-MSP. Offspring from these matings yielded

4 DPI

7 DPI

35 DPI
Pri/Pre miR-21

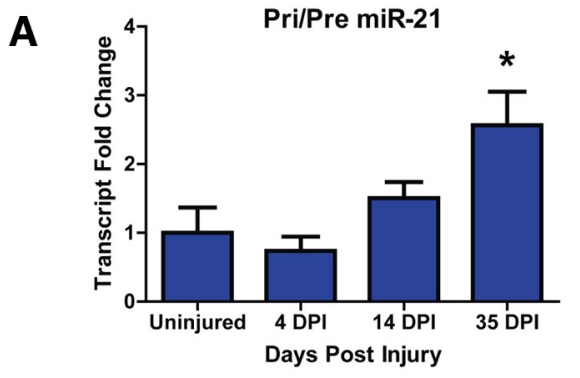

B

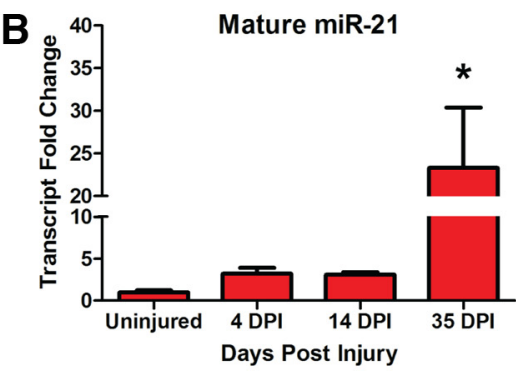

GFAP mature miR-21

mature miR-21

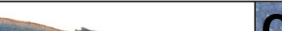
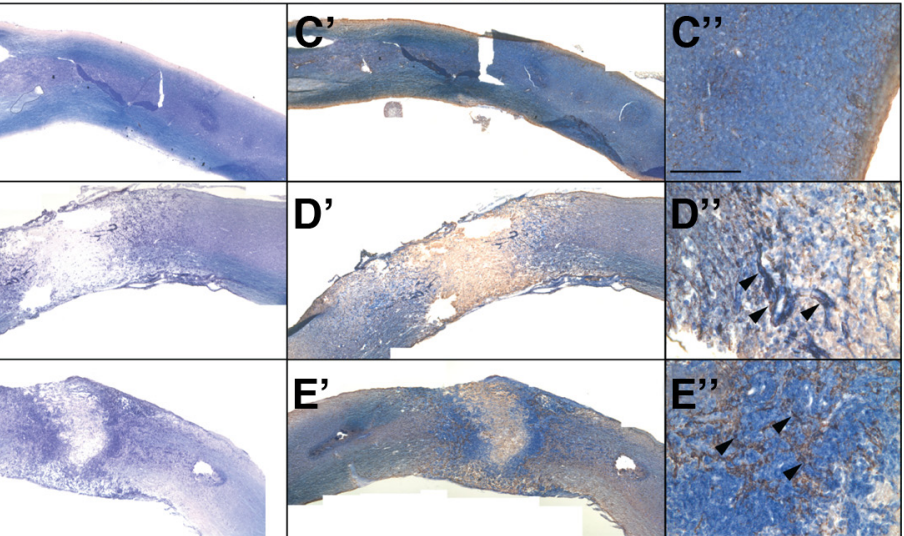

Figure 1. miR-21 is expressed after severe spinal cord injury. RNA was extracted from injured spinal cord 4, 14, and $35 \mathrm{DPI}$, as mature miR-21 revealed expression around lesion area Scale bar, $500 \mu \mathrm{m}$. $\mathbf{C}^{\prime}-\mathbf{G}^{\prime}$, Immunohistochemistry for GFAP revealed colocalization with mature miR-21, especially in astrocytes adjacent to lesion site ( $C^{\prime \prime}-G^{\prime \prime}$ arrowheads). Scale bar, $200 \mu \mathrm{m}$.

the following four genotypes: (1) GFAP-Cre;ROSA-miR21/+ (-MSP/ + ), (2) GFAP-Cre, (3) ROSA-miR21/+ (-MSP/+), and (4) ROSA-+/+. Transgene expression was not detected in the last three genotypes and served as wild-type (WT) controls.

Mouse spinal cord injury and animal care. All animal procedures were performed in accordance with the Public Health Service Policy on Humane Care and Use of Laboratory Animals and all procedures were approved by the Northwestern University Institutional Animal Care and Use Committee. Transgenic and WT mice (8-10 weeks of age of both sexes) were anesthetized by inhalation of $2.5 \%$ isoflurane anesthetic in 100\% oxygen administered by VetEquip Rodent anesthesia machine. A T11 vertebral laminectomy was performed to expose the spinal cord. The spinal cord was injured using an IH-0400 Spinal Cord impactor (Precision Systems and Instrumentation) with a $1.25 \mathrm{~mm}$ tip with $70 \mathrm{Kdynes}$ of force and $60 \mathrm{~s}$ of dwell time. Skin was sutured using AUTOCLIP $(9 \mathrm{~mm}$; $\mathrm{BD}$ Biosciences). For postoperative care, mice were kept on a heating pad for $24 \mathrm{~h}$ to maintain body temperature. Mice were given Metacam (1 $\mathrm{mg} / \mathrm{kg}$, s.c.) and Gentamycin (5 mg/kg, s.c.) to minimize discomfort and infection. Bladders were manually expressed twice daily. A 5 d Gentamycin treatment course $(5 \mathrm{mg} / \mathrm{kg}$ daily, s.c.) was started in the event of hematuria.

RNA extraction and real-time reverse transcriptase PCR. For total RNA extraction from injured spinal cord tissue, 4-mm-long tissue containing 
A ROSA26 Targeting Construct

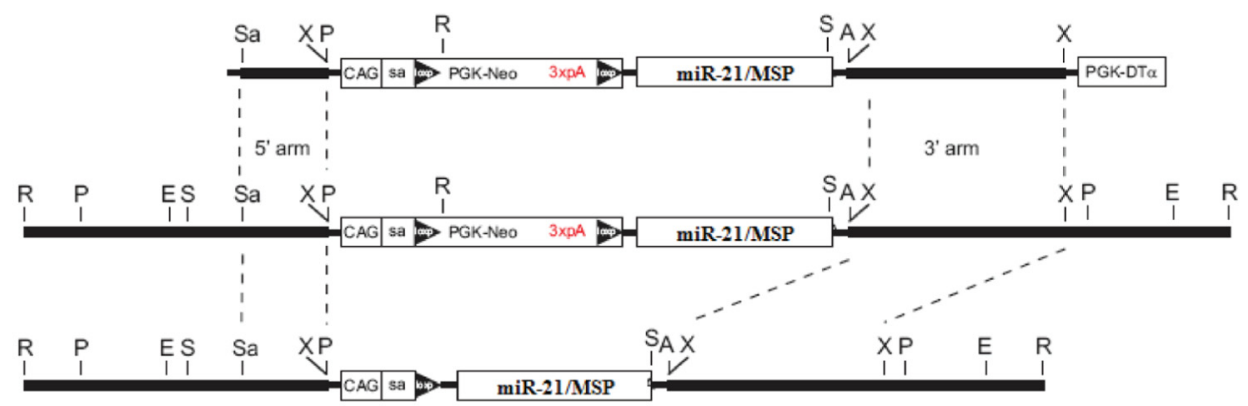

B

Targeted ROSA26 Locus (flx
(miR-21/MSP is NOT expressed)
Targeted ROSA26 Locus
afterCre-mediated Excision
(miR-21/MSP IS expressed)

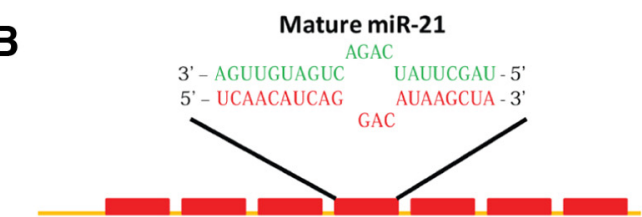

miR-21 Sponge in 3'UTR of Transcript
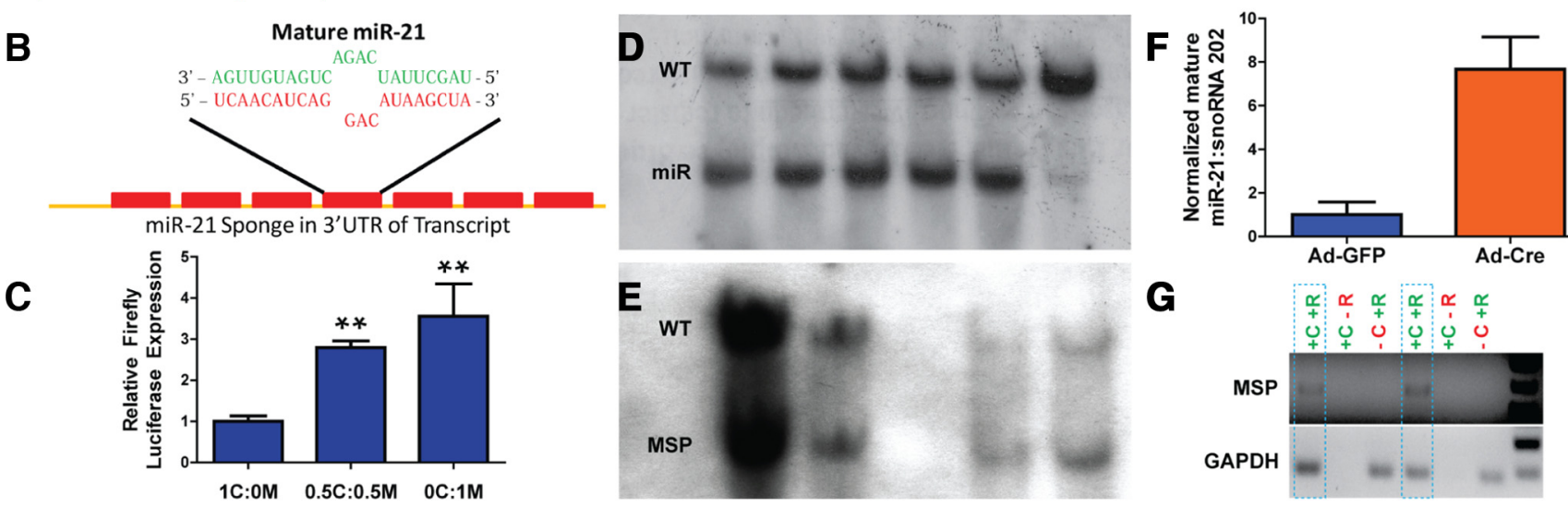

Figure 2. Design and validation of transgenic mice that overexpress or inhibit miR-21.A, Murine primary mir-21 and miR-21 sponge (MSP) sequence was inserted into R0SA26 targeting construct $3^{\prime}$ to PGK-neomycin cassette containing a trimer of the SV40 polyadenylation sequence ( $\left.3 \times \mathrm{PA} A\right)$ flanked by loxP sites. The transgene is driven by a CAG promoter with a splice acceptor site (SA). This design allows for controlled expression of primary miR-21 or MSP via recombination of loxP sites by Cre-recombinase protein. (A, Ascl; E, EcoRV; P, Pacl; R, EcoRl; S, Sall; Sa, Sacll; X, Xbal.) See Material and Methods for transgenic mouse generation. $B$, MSP transcript contains seven repeats of sequence complimentary to mature miR-21. Base pair mismatch minimizes enzymatic degradation of MSP-miR-21 pair. C, Functional inhibition of mature miR-21 by MSP was tested in HEK 293T cells. Increasing amounts of pCMV-d2eGFP-miR21 (M) compared withpCMV-d2eGFP-CXCR4 (C) sequestered miR-21, allowing for increased expression of pCMV-Luc-miR21-B (firefly luciferase). (1C:0M—pCMV-d2eGFP-CXCR4 plasmid only, 0.5C:0.5M- equal amounts of pCMV-d2eGFPCXCR4 and pCMV-d2eGFP-miR21. 0C:1M-pCMV-d2EGFP-miR21 only.) $n=3,{ }^{* *} p<0.01$ by ANOVA, compared with 1C:0M. D, E, Southern blot analyses for $5^{\prime}$ integration of R0SA26 targeting construct for miR-21 and MSP mice, respectively. Five clones and WT are shown for ROSA-miR21. Four clones are shown for MSP. F, ROSA-miR21 ES cells confirmed ROSA26 integration by Southern blot and PCR exhibited $\sim 8$-fold mature miR-21 expression when infected with Ad-Cre compared with Ad-GFP. G, Similarly, confirmed ROSA-MSP ES cells expressed MSP RNA in the presence of Cre $(+C)$ and when RNA was processed by reverse transcriptase $(+R)$. GAPDH served as control for qPCR. Two clones outlined by dashed lines are shown.

the lesion site was processed with Trizol (Invitrogen) and RNAqueousMicro kit (Ambion). Four-millimeter-long tissue of same vertebral position was collected from uninjured spinal cords. For mRNA studies, 500 ng of RNA was used to generate cDNA using oligo-dT primers (Thermoscript RT-PCR kit, Invitrogen). Real-time PCR was performed using SybrGreen Master Mix (Applied Biosystems) and Realplex ${ }^{2}$ Mastercycler (Eppendorf, cycling parameters: $95^{\circ} \mathrm{C} 15 \mathrm{~s}, 60^{\circ} \mathrm{C} 60 \mathrm{~s}$ for 40 cycles). Reactions were analyzed on $2 \%$ agarose gel to visualize MSP and GAPDH (loading control) amplification products.

The following primers were used: GAPDH forward, GTCGTGGATCTGACGTGCC; GAPDH reverse, TGCCTGCTTCACCACCTTC; MSP RT-PCR forward, TGAGGACAAACTCTTCGCGGTCTT; MSP RT-PCR reverse, TTTAAACGGGCCCGCGAT; Pri/Pre forward, GAT ACCAAAATGTCAGACAGCCC; Pri/Pre reverse, TGTACCACCT TGTCGGATAGCT.

For mature miR-21 and snoRNA202 (loading control) RT-PCR, 10 ng of total RNA was used and processed with Taqman gene-specific RT primers and probes (Applied Biosystems) following manufacturer's protocols.

Tissue processing and immunohistochemistry. Mice were killed with $\mathrm{CO}_{2}$ inhalation, perfused transcardially with cold HBSS (Lonza), and then fixed with $4 \%$ paraformaldehyde in PBS. Spinal cords were dissected and fixed for $2 \mathrm{~h}$ at $4^{\circ} \mathrm{C}$ in $4 \%$ paraformaldehyde. Spinal cords were equilibrated in $30 \%$ sucrose in PBS overnight, then embedded in TissueTek OCT embedding compound (Sakura), frozen on dry ice, and stored at $-80^{\circ} \mathrm{C}$.

Twenty-five micrometer thick frozen longitudinal sections were cut on Leica CM3050S cryostat and collected on Superfrost Plus slides (VWR). Every eleventh section was placed on the same slide such that each section was $250 \mu \mathrm{m}$ from the previous one on the slide. Five sections were placed on each slide, spanning $1250 \mu \mathrm{m}$ of the width of the spinal cord to ensure that the injury area was captured. Sections were kept at $-80^{\circ} \mathrm{C}$ until staining. For immunohistochemistry, slides were thawed to room temperature and washed $3 \times$ PBS for $5 \mathrm{~min}$, incubated in $10 \%$ donkey serum in PBS $0.1 \%$ Triton X-100 for $1 \mathrm{~h}$ at room temperature. Slides were then incubated with primary antibodies diluted 1:1000 in 1\% BSA in PBS $0.1 \%$ Triton X-100. The following day, slides were washed $3 \times$ PBS $0.1 \%$ Triton X-100 for 5 min, incubated with Alexa Fluorconjugated antibodies (Invitrogen, 1:1000) and Hoechst nuclear stain $(1: 1000)$ for $1.5 \mathrm{~h}$ at room temperature. Slides were again washed $3 \times$ PBS $0.1 \%$ Triton X-100 for 5 min, then mounted with Prolong Gold anti-fade reagent (Invitrogen). The following primary antibodies were used: GFAP (Dako rabbit IgG; Sigma mouse $\operatorname{IgG}_{1}$ ), galectin-3 (R\&D systems goat $\operatorname{IgG}$ ), vimentin (Millipore chick IgY), and SMI-312 (Covance mouse $\left.\operatorname{IgG}_{1}\right)$.

Tissue imaging and fluorescence intensity measurements. Stained tissue sections from WT and transgenic mice were imaged using a Leica DM6000 confocal microscope as described by Sahni et al. (2010). Briefly, the number of tissue sections that contained the spinal cord injury was counted for each animal. The middle of the lesion was then determined and that corresponding section, as well as the sections $250 \mu \mathrm{m}$ lateral to it, were imaged. Imaging focused on the lesion area as well as tissue within $1000 \mu \mathrm{m}$ rostral and caudal to the lesion. Each section was scanned with identical laser power, amplification gain, offset values, and number of stacks, as well as imaged in the same session to avoid signal fading. Confocal Z-stacks were then processed with ImageJ, using the Z-project feature to sum Z-slices to create one two-dimensional image for each channel. Mean gray area was measured for each channel. 
Authors were blinded with respect to the experimental groups during all imaging and fluorescence intensity measurements.

For axon density measurements, GFAP- and SMI-312-stained sections were imaged as described above and analyzed using the Feature J Hessian ImageJ plugin (Grider et al., 2006; Sahni et al., 2010). Z-stacks for each channel were summed together using Z-project and processed using the "smallest eigenvalue" with the smoothing scale set to 1.0. Monochrome images were opened in Adobe Photoshop CS4 and the interior of the lesion (demarcated by the edge of GFAP expression) was outlined and corresponding SMI-312 area was selected. This area was imported into ImageJ and SMI-312 staining was measured to determine percentage of lesion area with SMI-312 staining.

miRNA in situ hybridization. In situ hybridization was performed as described previously (Obernosterer et al., 2007). Briefly, tissue sections were incubated overnight with miRCURY LNA 5'-,3'-digoxigenin (DIG) double labeled mature miR-21 probe (Exiqon) at $53^{\circ} \mathrm{C}$. The next day, slides were incubated overnight with anti-DIG alkaline phosphataseconjugated antibody (Roche, 1:2000). Alkaline phosphatase substrate deposition using NBT/ $\mathrm{BCIP}$ reaction was performed and sections were imaged using an Olympus BX50 microscope with a Spot Insight 6 camera. Slides were then washed in PBS and incubated with rabbit anti GFAP antibody (Dako, 1:1000), diluted in $1 \%$ BSA PBS $+0.1 \%$ Triton X-100 overnight. Slides were then washed $3 \times$ PBS $0.1 \%$ Triton X-100 and stained with DAB Peroxidase (Vector Labs). Images of the same sections as above were taken.

miR-21 sponge luciferase validation. HEK $293 \mathrm{~T}$ cells were transfected using Lipofectamine 2000 following the manufacture's protocol (Invitrogen). Plasmids were transfected as previously described (Ebert et al., 2007) using the following ratio: $0.1 \mathrm{x}$ TKRenilla (gift from Anjen Chenn laboratory, University of Illinois at Chicago, Chicago, IL), 1x pCMV-luc-miR21-B (Addgene), and $8 \mathrm{x}$ combination of pCMV-d2eGFP-CXCR4 and pCMV-d2EGFP-21 (Addgene). Luciferase activity was determined $24 \mathrm{~h}$ after transfection using the Dual Luciferase Reporter System (Promega), allowing for simultaneous detection of luciferase and renilla transfection control.

Statistical analyses. For all comparisons between WT and transgenic mice, Student's unpaired $t$ test was used. For comparison of transcripts expressed after spinal cord injury in WT mice and luciferase expression in HEK $293 \mathrm{~T}$ cells, one-way ANOVA single factor was performed followed by Tukey's post hoc $t$ test for comparison within groups. $p$ values $<0.05$ were deemed significant. Values in graphs are shown as mean \pm SEM.

\section{Results}

Mature miRNA-21 expression is increased adjacent to lesion sites following severe SCI

Adult C57BL/6 mice received severe automated impaction injuries followed by persistent compression of the spinal cord, anal-
A

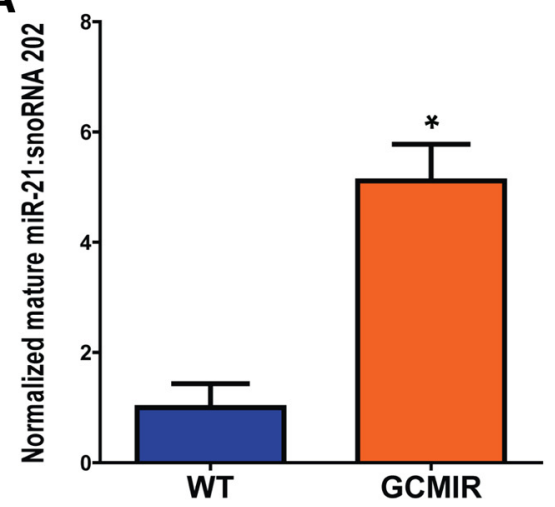

C
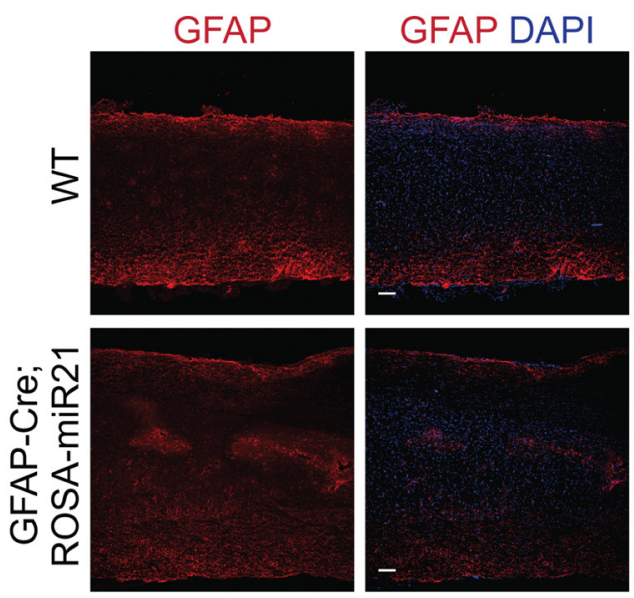

$\mathbf{E}$
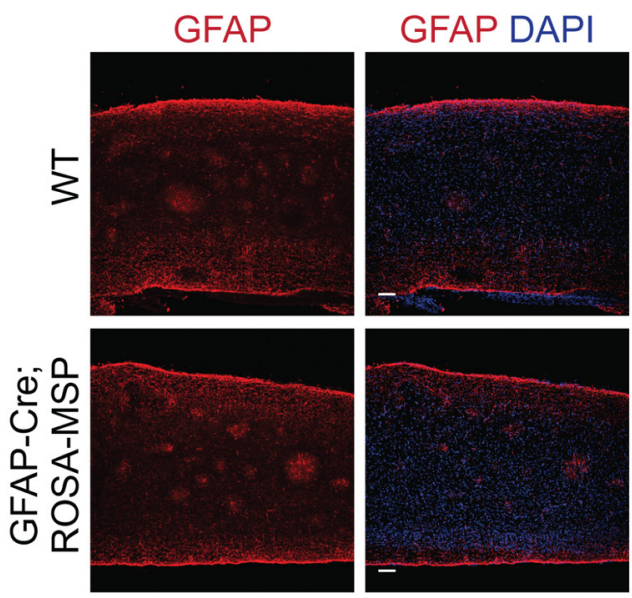

B

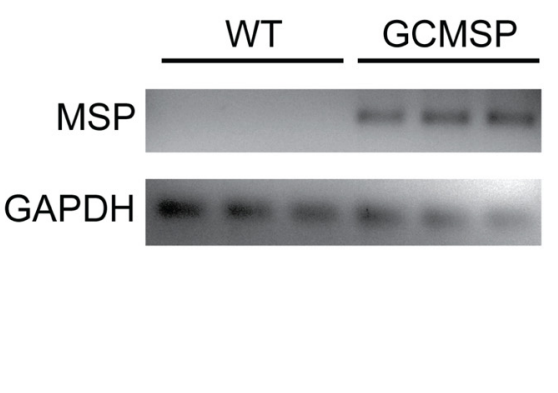

D
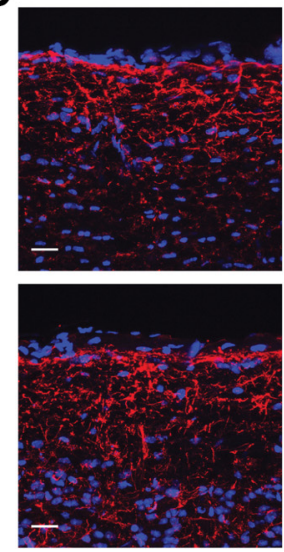

$\mathbf{F}$
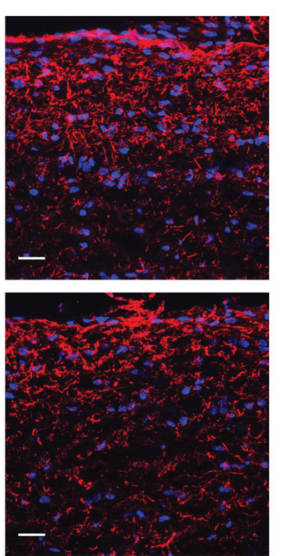

Figure 3. Modulation of miR-21 does not affect astrocytes under homeostatic conditions. $A$, Uninjured spinal cords from GCMIR expressed fivefold more mature miR-21 compared with WT as detected by qPCR. B, Similarly, MSP expression was detected by qPCR in GCMSP uninjured spinal cords but not WT. C, D, No differences from WT and GCMIR spinal cord astrocytes were observed at low and high magnification, respectively. $E$, $F$, Likewise, astrocytes from WT and GCMSP spinal cords were indistinguishable at low and high magnification, respectively. Scale bars: $\boldsymbol{C}, \boldsymbol{E}, 100 \mu \mathrm{m} ; \boldsymbol{D}, \boldsymbol{F}, 25 \mu \mathrm{m} .{ }^{*} p<0.02$.

ogous to most human SCI (Scheff et al., 2003; Engesser-Cesar et al., 2005). RNA was extracted from uninjured spinal cords as well as spinal cords 4,14 , and $35 \mathrm{~d}$ postinjury (DPI), encompassing both acute and chronic stages of astrogliosis following SCI (Sahni et al., 2010). To determine levels of primary and precursor miR-21 (Pri/Pre miR-21) by quantitative real-time PCR (qPCR), we used primers that bind to the $5^{\prime}$ and $3^{\prime}$ ends of the premiRNA, thereby amplifying both the primary and precursor transcripts (Bartel, 2004; Sahni et al., 2010). Pri/Pre miR-21 was 
A
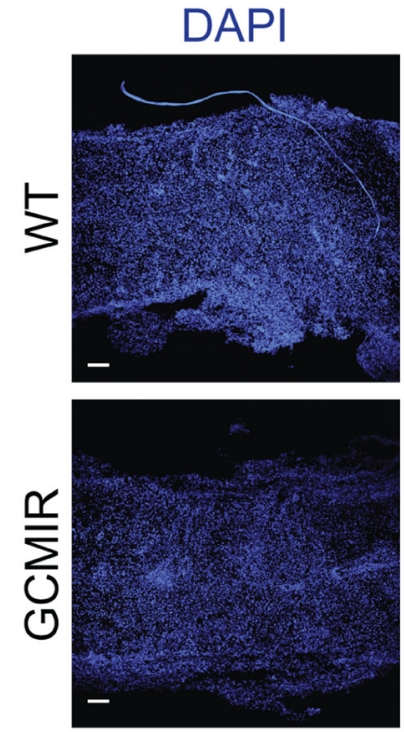

B
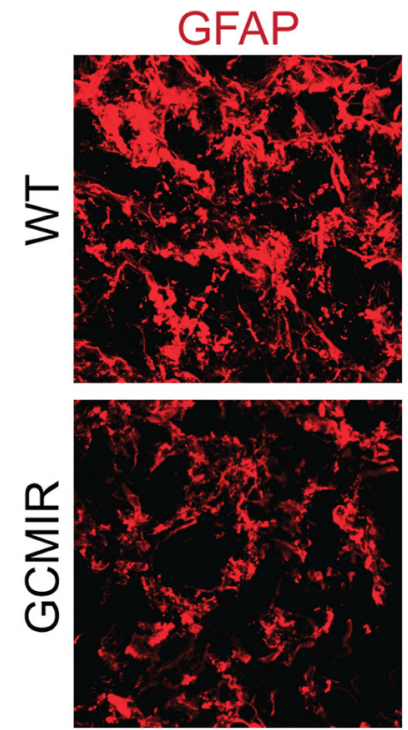

D
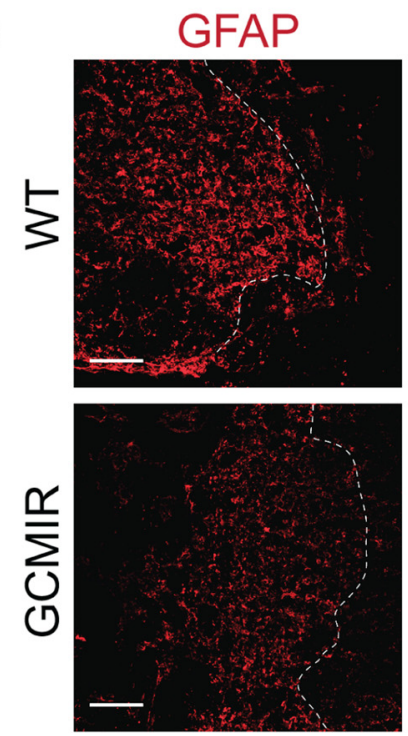

GFAP
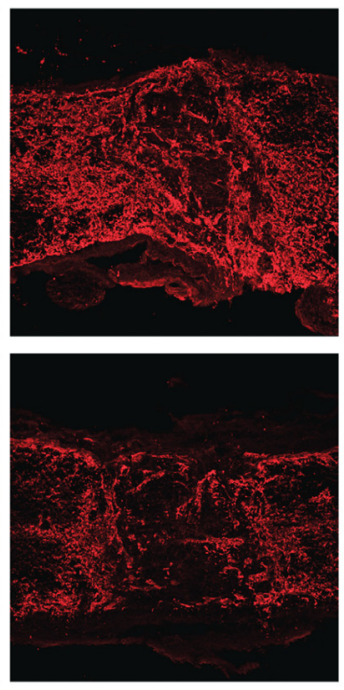

GFAP DAPI
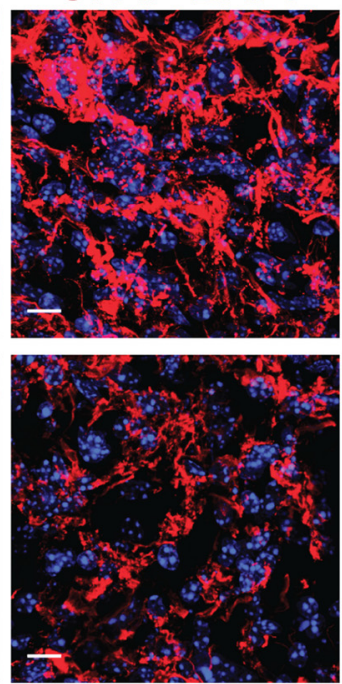

Vimentin
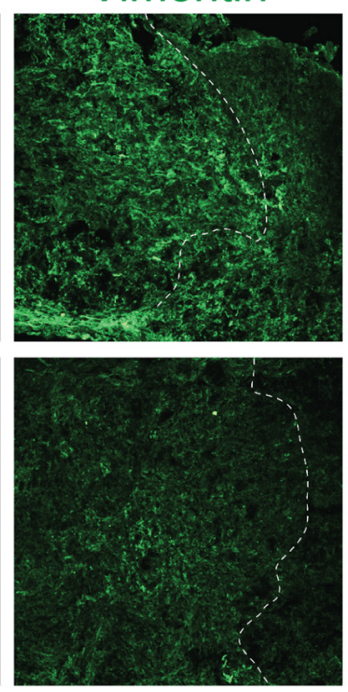

Galectin 3
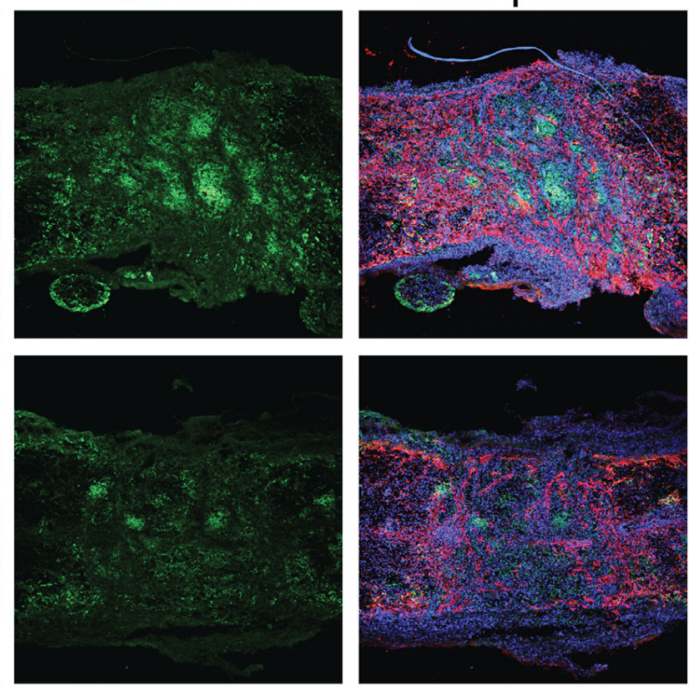

C
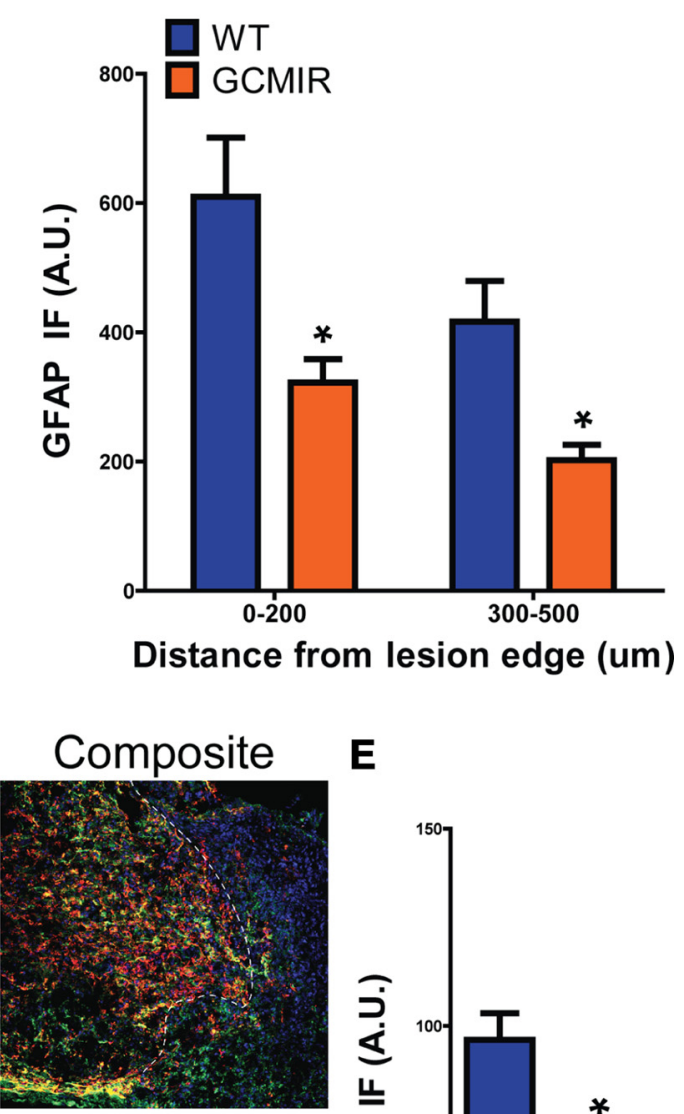

E

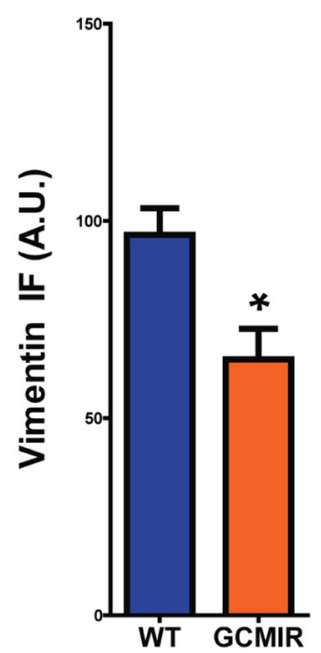

Figure 4. miR-21 attenuates astrocytic hypertrophy 14DPI after SCI. WT and GCMIR21 mice were analyzed 14 DPI after SCI. A, Longitudinal cross-sections revealed that astrocytes were less hypertrophic and expressed less GFAP (red) in GCMIR21 mice compared with WT. Compaction by astrocytes of activated microglia marker Galectin $3+$ (green) was also (Figure legend continues.) 
increased by 1.5 -fold at 14 DPI and 2.5 -fold by 35 DPI (Fig. $1 \mathrm{~A}$ ) compared with uninjured spinal cord. Levels of mature miR-21 were increased threefold at both 4 and 14 DPI but were increased 23 -fold at 35 DPI (Fig. 1 B). The much greater increase in mature miR-21 compared with Pri/Pre miRNA at 35 DPI suggests enhanced processing into the mature form rather than increased expression of the primary and/or precursor transcripts.

Mature miR-21 was detectable at low levels by in situ hybridization in uninjured spinal cord (Fig. $1 C-C$ "). However, by 4 DPI mature miR-21 expression was increased in cells $500 \mu \mathrm{m}$ rostral and caudal to the injury site (Fig. $1 D-D^{\prime}$ ), and by 7 and 14 DPI abundant expression was found in cells bordering the lesion area (Fig. 1E, F'). By 35 DPI, mature miR-21 expressing cells were found both around the lesion area and condensed within the lesion core. Our previous findings indicated that cultured astrocytes express mature miR-21 (Sahni et al., 2010). To determine whether astrocytes express miR-21 in vivo following SCI, we costained for GFAP protein, a marker of astrocytes. At 4, 7, and 14 DPI, GFAP-expressing cells bordering the injury site expressed mature miR-21 (Fig. 1D"-F", arrowheads), and by 35 DPI GFAP-expressing cells both bordering the lesion and within it expressed the miRNA (Fig. 1G", arrowheads). Thus astrocytes express increased levels of miR-21 after SCI with the most abundant expression occurring during the later phase of astrogliosis.

\section{Generation of transgenic mice to modulate miR-21 function in astrocytes}

Based on these findings, we hypothesized that miR-21 has a crucial function in astrocytic response following SCI. To investigate this, we generated mice that contain transgenes that conditionally either express or inhibit mature miR-21 from the ROSA26 locus. ROSA26 locus is an ideal genomic locus because it is easily targeted for transgene insertion and is expressed ubiquitously in all cell types (Srinivas et al., 2001). The mouse pri-miR-21 sequence was cloned into the pCAG-BigT vector, placing it $3^{\prime}$ to a neomycin selection cassette with a transcriptional stop signal flanked by loxP sites and driven by the CAG promoter (Fig. $2 A$ ). The addition of the CAG promoter to the targeting construct was designed to enhance transgene expression from the ROSA26 locus. This arrangement allowed for cell-specific expression by permitting transgene expression only in cells that also express Crerecombinase (Srinivas et al., 2001). The pCAG-BigT-ROSAmiR21 plasmid was then cloned into pROSA26-PA and recombined into the ROSA26 locus in C57BL/6 ES cells. Targeted ES clones were screened by PCR for homologous recombination into the ROSA26 locus (data not shown). ES clones positive by PCR were then further confirmed by Southern blot analysis using a probe hybridizing to the $5^{\prime}$ arm (Fig. 2D) and $3^{\prime}$ arm (data not shown) of the ROSA26 locus. Five appropriately targeted ES clones were expanded and infected with adenovirus expressing either Cre recombinase (Ad-Cre) or GFP (Ad-GFP) to characterize mature miR-21 expression. ES clones expressed $\sim 8$-fold higher levels of mature miR-21, as detected by qPCR, when in-

\footnotetext{
(Figure legend continued.) reduced in GCMIR21 mice compared with WT. Scale bar, $100 \mu \mathrm{m}$. $B$, Magnified images of astrocytes adjacent to lesion showed smaller astrocytes with thinner processes in GCMIR21 mice compared with WT. (GFAP, red; DAPI, blue.) Scale bar, $10 \mu \mathrm{m}$. C, Quantification of GFAP immunofluorescence (IF; arbitrary units, A.U.) $0-200 \mu \mathrm{m}$ and $300-500$ $\mu \mathrm{m}$ away from lesion edge. $\boldsymbol{D}$, Vimentin immunofluorescence (green) is also reduced in astrocytes adjacent to injury site in GCMIR21 mice compared with WT. Dashed white lines indicate lesion edge. Scale bar, $100 \mu \mathrm{m}$. $\boldsymbol{E}$, Quantification of vimentin staining within $200 \mu \mathrm{m}$ of injury site. $n=4,{ }^{*} p<0.05$ by Student's $t$ test.
}

fected with Ad-Cre compared with Ad-GFP, indicating Cre recombination of loxP sites allowed for pri-miR-21 transcription and proper processing into mature miR-21 (Fig. $2 F$ ). Three targeted ES clones were used to generate chimeric mice and male chimeras were mated with $\mathrm{C} 57 \mathrm{BL} / 6$ females to generate three founder lines. These lines were found to be similar as they exhibited germ line transmission and transgene expression in cultured neural cells when infected with Ad-Cre (data not shown). One line, designated ROSA-miR21, was used for subsequent studies.

We used miRNA sponge technology to generate transgenic mice that inhibited miR-21 function (Ebert et al., 2007). The miR-21 sponge (MSP) is a transcript that contains seven repeats of a 21-nucleotide sequence that is complimentary to mature miR-21, thereby acting as an inhibitor or "sponge" to compete for mature miR-21 away from endogenous targets (Fig. 2B). miRNA sponge technology has been used effectively to inhibit the in vivo function of other miRNAs (Dey et al., 2011; Luikart et al., 2011; Ma et al., 2011). A three nucleotide sequence containing base pair mismatches with mature miR-21 is present in the repeat sponge sequence to prevent enzymatic degradation of the MSPmature miR-21 complex (Bartel, 2004; Ebert et al., 2007). We tested the functionality of the MSP in 293T cells, which express mature miR-21 (Ebert et al., 2007). 293T cells were transfected with pCMV-Luc-miR21-B (which expresses firefly luciferase transcript containing a miR-21 sponge in the $3^{\prime}$ UTR), Tk-Renilla luciferase (to serve as transfection control), as well as varying ratios of pCMV-d2eGFP-miR21 (destabilized eGFP with miR-21 sponge in 3'UTR) and pCMV-d2eGFP-CXCR4 (destabilized eGFP with a non-binding sponge sequence CXCR4, see Materials and Methods). As increasing amounts of pCMV-d2eGFP-miR21 were transfected into 293T cells, the d2eGFP-miR21 transcript competed for endogenous miR-21 away from the miR-21 binding firefly luciferase transcript. This relieved the translational repression on firefly luciferase by miR-21, thereby increasing firefly luciferase expression, indicating that MSP functionally inhibits miR-21 (Fig. 2C). The MSP sequence was cloned into pCAGBigT and ROSA26-targeted ES clones were generated as described above. These clones were confirmed by PCR and Southern blot analyses (Fig. 2E). Additionally, as the MSP transgene does not express an endogenous molecule, qPCR amplification of MSP was only seen in RNA from Cre-infected targeted ES cells processed in the presence of reverse transcriptase enzyme (Fig. 2G). One line, designated ROSA-MSP, was used for subsequent studies.

\section{miR-21 regulates astrocytic response after severe SCI}

We investigated the role of miR-21 in astrocytes by mating the ROSA-miR21 and ROSA-MSP mice with a GFAP-Cre line (73.12), in which Cre expression is under the control of a modified sequence of the full mouse GFAP gene (Garcia et al., 2004). These matings resulted in mice with astrocytes that either overexpressed miR-21 (GFAP-Cre;ROSA-miR21, GCMIR) or inhibited miR-21 function (GFAP-Cre;ROSA-MSP, GCMSP). Litters contained Mendelian ratios of genotypes and transgenic mice exhibited no gross developmental or behavioral abnormalities. Expression of mature miR-21 and MSP was confirmed in uninjured spinal cords (Fig. 3A,B). Examination of uninjured spinal cords from transgenic mice revealed that astrocytes appeared similar compared with those of WT controls (Fig. $3 C-F$ ). These findings indicated that miR-21 does not have a significant role in astrocyte homeostasis.

However, modulation of miR-21 led to profound differences in astrocytes after SCI. In WT injured spinal cords at 14 DPI, 
A
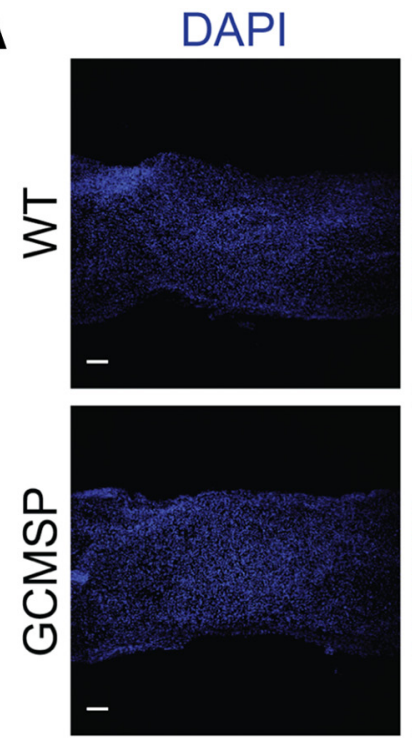

B
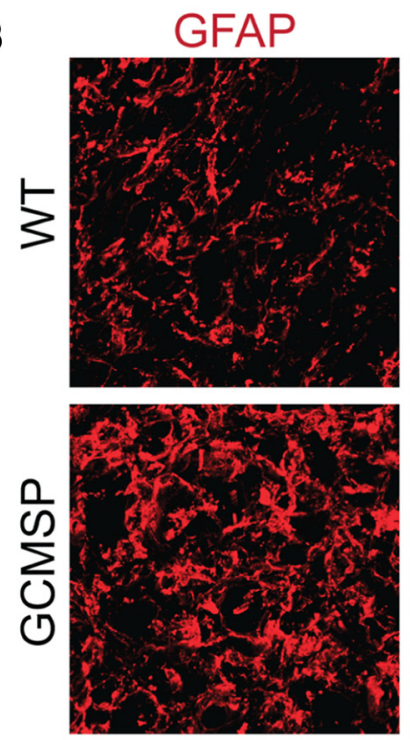

D
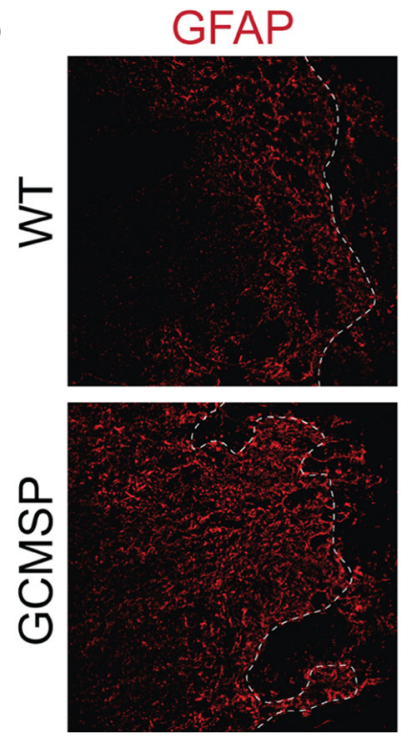
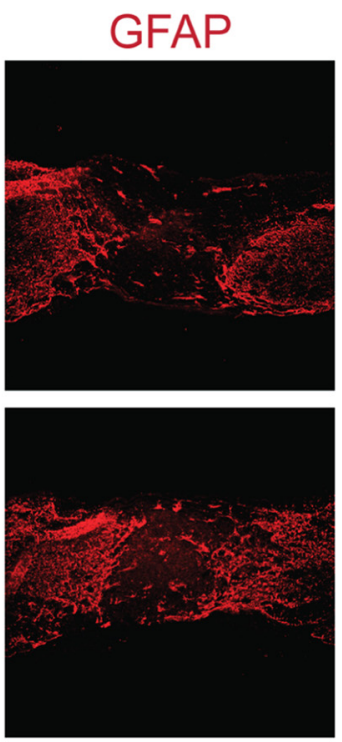

GFAP DAPI
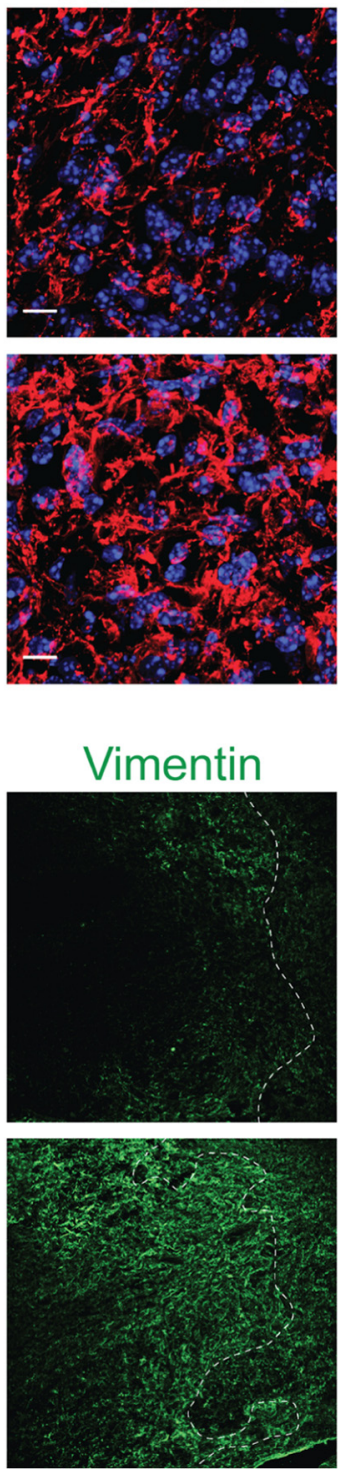
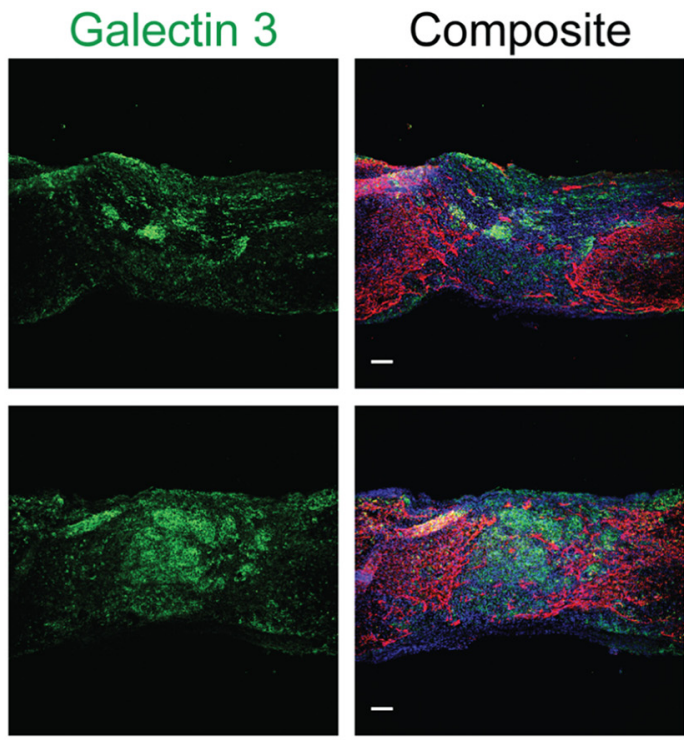

C

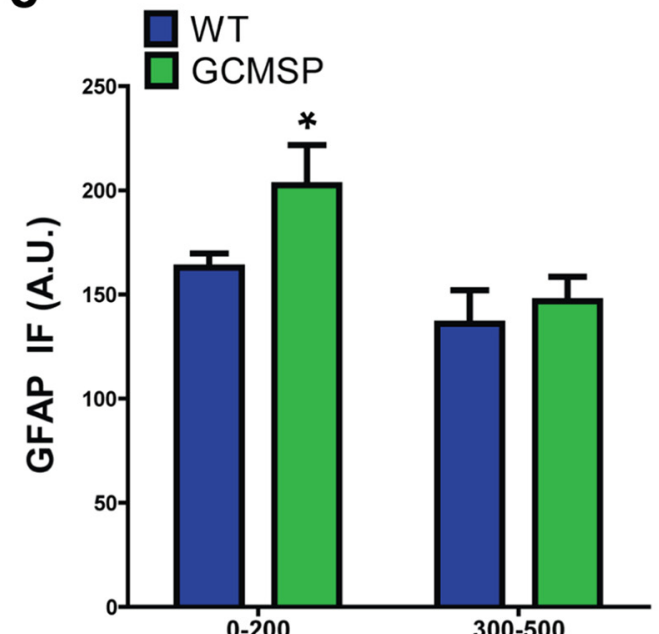

Distance from lesion edge (um)

Composite
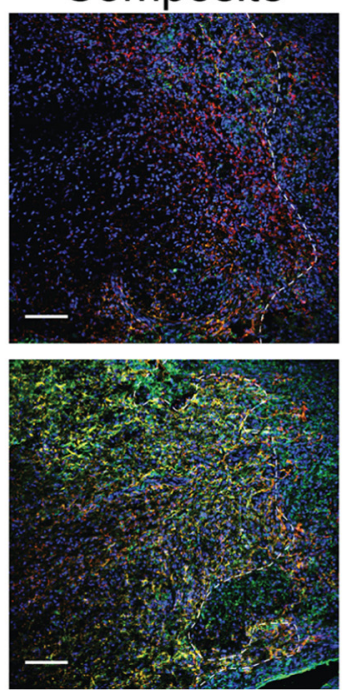

E

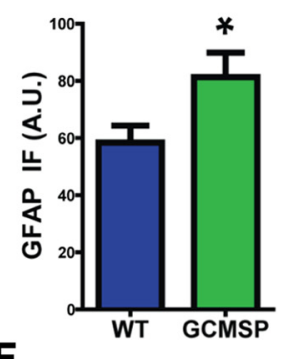

Composite

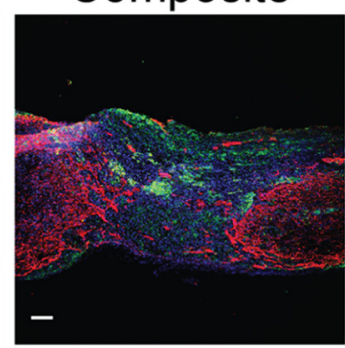

$F$

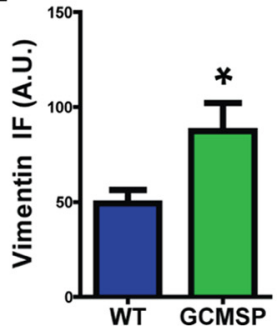

Figure 5. Inhibition of miR-21 function enhances astrocytic hypertrophy 14DPI after SCI. WT and GCMSP mice were analyzed $14 \mathrm{DPI}$ after SCI. A, In GCMSP injured spinal cord, astrocytes displayed more GFAP (red) immunofluorescence and were hypertrophic with thicker processes compared with WT. Distribution of galectin $3+$ microglia (green) was unchanged. (Figure legend continues.) 
astrocytes adjacent to the lesion exhibited hypertrophic somata and processes with increased GFAP immunofluorescence, characteristic of reactive astrocytes (Fawcett and Asher, 1999; Barnabé-Heider and Frisén, 2008; Sahni et al., 2010). In contrast, lesion-adjacent astrocytes in GCMIR mice were smaller with thinner processes (Fig. 4A,B). Quantification of GFAP immunofluorescence showed a marked reduction in GCMIR mice within $200 \mu \mathrm{m}$ of the lesion site as well as $300-500 \mu \mathrm{m}$ away (Fig. $4 C$ ). Further, vimentin immunofluorescence, which is also increased in reactive astrocytes, was significantly reduced in GCMIR mice (Fig. 4D,E). Notably the lesion size was approximately $80 \%$ larger in GCMIR mice compared with WT control (WT, 155,988 \pm 971 $\mu \mathrm{m}^{2}$; GCMIR, 276,169 $\pm 351 \mu \mathrm{m}^{2}, n=4$ mice, $\left.p<0.03\right)$. Moreover, compaction of galectin-3+ cells, a specific marker for activated microglia (Byrnes et al., 2009; Byrnes et al., 2011), was prominent around the lesion area in WT-injured spinal cords but was less apparent in GCMIR-injured cords (Fig. 4A,B). These data demonstrate that miR-21 attenuated formation of reactive hypertrophic astrocytes, and that the astrocytic changes were associated with an increase in lesion size and a reduction in microglial compaction. miR-21 has been shown to increase proliferation of some cell types (Si et al., 2007; Moriyama et al., 2009; Wang et al., 2009). We examined expression of Ki67, a nuclear protein necessary for proliferation, and did not find any differences in numbers of Ki67-exressing cells at 14 DPI between WT- and GCMIR-injured cords (data not shown). Moreover, miR-21 has also been found to inhibit cell death (Krichevsky and Gabriely, 2009). However, we also did not detect any changes in cleaved caspase 3 (CC3) expression, a marker of apoptosis (data not shown).

Conversely in GCMSP mice at 14 DPI, lesion-adjacent astrocytes were more hypertrophic with denser processes compared with WT controls (Fig. 5A,B). GFAP staining intensity in GCMSP mice was increased nearly $40 \%$ within $100 \mu \mathrm{m}$ of the lesion edge and $24 \%$ within $200 \mu \mathrm{m}$ of the lesion (Fig. 5C,E). The heightened reactivity of the astrocytes was further evidenced by a significant increase in vimentin immunofluorescence (Fig. 5D,F). Thus, inhibiting miR-21 augmented the hypertrophic, reactive phenotype of astrocytes. However, compaction of microglia (Galectin $3+$ ) was not changed at 14 DPI in GCMSP mice (Fig. 5A). There was no difference in lesion size between GMSP- and WT-injured cords and there were no changes in numbers of Ki67+ and CC3+ cells around the injury area (data not shown). Thus, the observed increase in endogenous miR-21 at 14 DPI acts to limit astrocytic hypertrophy.

By 35 DPI, formation of the glial scar as well as an increase in astrocytes around the lesion has occurred (Barnabé-Heider et al., 2010). These astrocytes in the chronic stages of the glial scar have finer processes and smaller somata compared with astrocytes at 14 DPI (compare WT in Fig. $4 A, B$ to Fig. $6 A, B$ ). The number of astrocytes surrounding the lesion area did not differ between WT and GCMIR mice (Fig. 6A,B). However, GFAP immunofluorescence was significantly reduced within $200 \mu \mathrm{m}$ of the lesion area in the GCMIR mice (Fig. 6C). Vimentin staining was also significantly reduced in GCMIR animals (Fig. 6D,E).

$\leftarrow$

(Figure legend continued.) Scale bar, $100 \mu \mathrm{m}$. B, Higher magnification of astrocytes adjacent to injury demonstrates increased hypertrophy in GCMSP mice. Scale bar, $10 \mu \mathrm{m}$. C, Quantification shows increased GFAP staining $0-200 \mu \mathrm{m}$ from injury site. D, GFAP (red) and vimentin (green) immunofluorescence is increased adjacent to injury site in GCMSP mice. $\boldsymbol{E}, \boldsymbol{F}$, Quantification of GFAP and vimentin staining, respectively, $0-100 \mu \mathrm{m}$ from lesion edge. $n=4$ mice, ${ }^{*} p<0.05$ by Student's $t$ test. Dashed white lines indicate lesion edge.
In contrast, analysis of GCMSP cords at 35 DPI continued to show the opposite phenotype from the one observed in GCMIR animals. Astrocytes adjacent to the injury site in GCMSP mice remained hypertrophic compared with the finer processed astrocytes seen in the WT cords (Fig. 7A,B) with increased levels of GFAP staining within $200 \mu \mathrm{m}$ of the lesion area (Fig. $7 C$ ). Galectin-3+ microglia distribution was not significantly changed, although it trended toward an increase within $200 \mu \mathrm{m}$ of the injury site (WT, $84.1 \pm 9.0$ A.U.; GCMSP, $102.9 \pm 6.8, n=$ $3-6$ mice, $p=0.12$ ). Increased levels of vimentin staining adjacent to the injury site (Fig. $7 D, E$ ) provided further evidence of enhanced reactivity of astrocytes in GCMSP injured cords. Thus, inhibiting miR-21 function can sustain astrocytic hypertrophy into more chronic stages after SCI.

\section{Inhibition of miR-21 function contributes to a more permissive glial scar}

A major limitation in improving outcomes after SCI is presence of the glial scar, a hostile environment for axon regeneration. We immunostained injured spinal cords for the pan-axonal neurofilament marker SMI-312 (Masliah et al., 1993; Ulfig et al., 1998) at $35 \mathrm{DPI}$. As expected in a severely injured spinal cord, very few axons were present in the lesion area of WT animals (Fig. 8A). Strikingly, GCMSP lesion areas contained nearly twice as much SMI-312 staining, indicating an increased presence of axons within the injury site (Fig. $8 A-C$ ). In contrast, SMI-312 staining in GCMIR spinal cords was unchanged from WT (WT, $1.00 \pm$ $0.27 \%$ SMI-312+; GCMSP, $0.95 \pm 0.09, n=3-5$ mice, $p=0.83$ ). These findings suggest that inhibiting miR-21 function in astrocytes may offer a potential therapeutic approach for mitigating some of the deleterious effects of SCI.

\section{Discussion}

miR-21 is expressed at low levels in the uninjured spinal, and neither overexpression of miR-21 nor of the miR-21 sponge produced observable phenotypic changes in astrocytes in uninjured spinal cords. These findings suggest that the miRNA is not necessary to maintain homeostasis in astrocytes. However, levels of miR-21 increased significantly following SCI with the greatest expression of miR-21 observed at 5 weeks post-SCI. At that time there was a 2.5 -fold increase in pri/pre miR-21 but a 23 -fold increase in mature miR-21 levels, indicating that the increase predominantly reflected enhanced miR- 21 processing into the mature form rather than increased transcription of the primary form or processing into the precursor form. Such regulation of miRNA processing is a frequently observed mechanism for modulating the function of miRNAs (Newman and Hammond, 2010). miR-21 is not the only miRNA that changes levels of expression in response to spinal cord injury induced by various injury paradigms (Liu et al., 2009, 2010, 2012; Madathil et al., 2011; Strickland et al., 2011; Ziu et al., 2011), but changes in miR-21 are a consistent observation. Collectively these observations, coupled with the highly conserved sequence of mature miR-21, suggest that miR-21 is important for neural responses to injury.

Since we noted previously that miR-21 is expressed by cultured astrocytes (Sahni et al., 2010), we analyzed astrocytic expression of miR-21 after SCI by in situ hybridization for mature miR-21. Mature miR-21 was expressed in GFAP+ astrocytes adjacent to the lesion site at both early and later stages of the glial response to injury, and levels of elevated expression were maintained in astrocytes during the entire 5 weeks of our analyses. Although astrocytes are not the only cell that expressed miR-21 in 
A
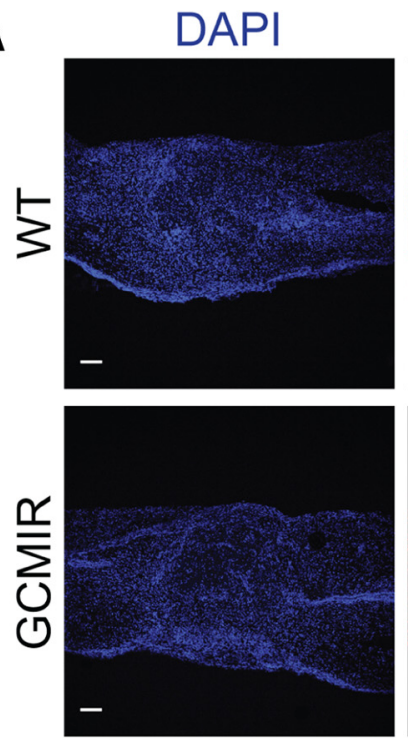

B
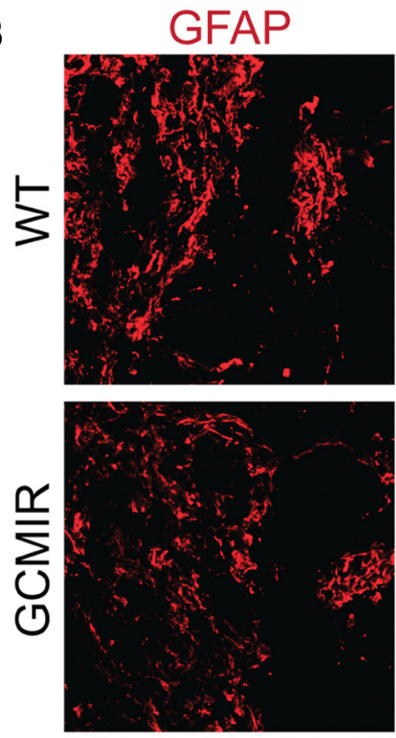

D
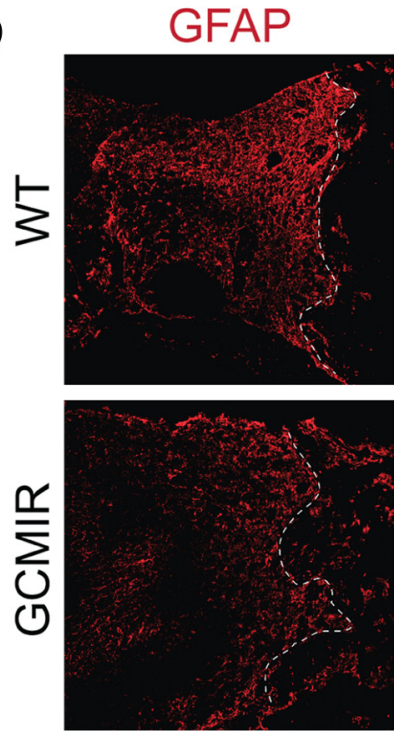
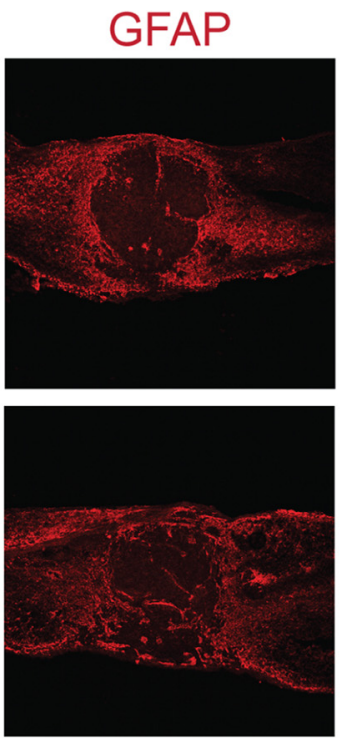

GFAP DAPI
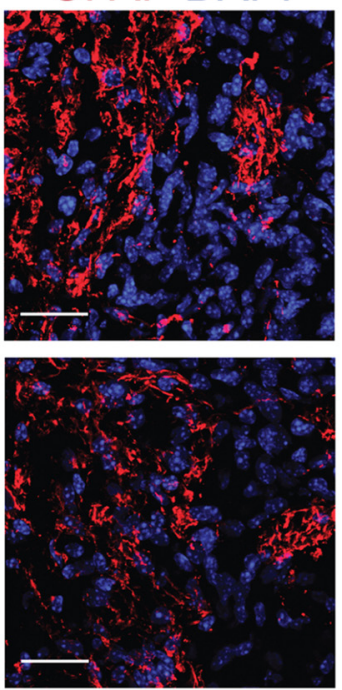

Vimentin
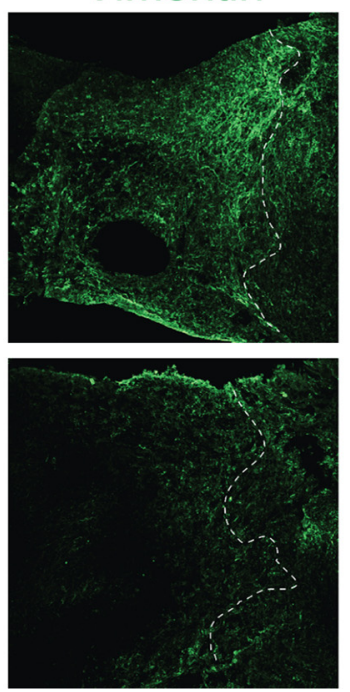
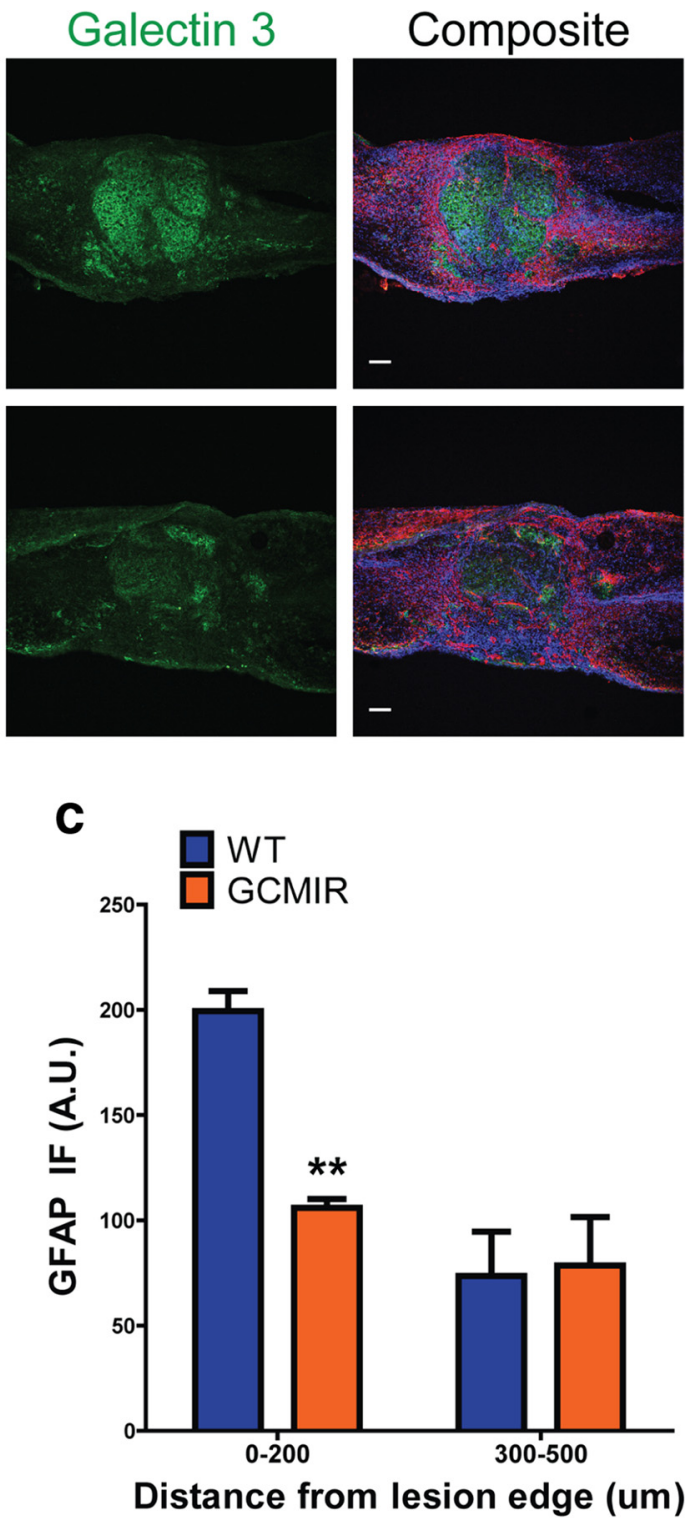

Composite

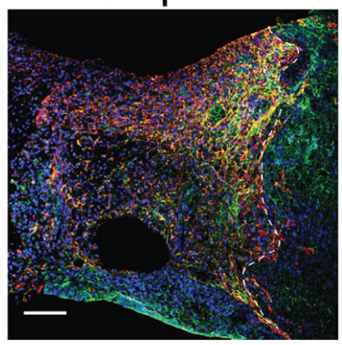

E

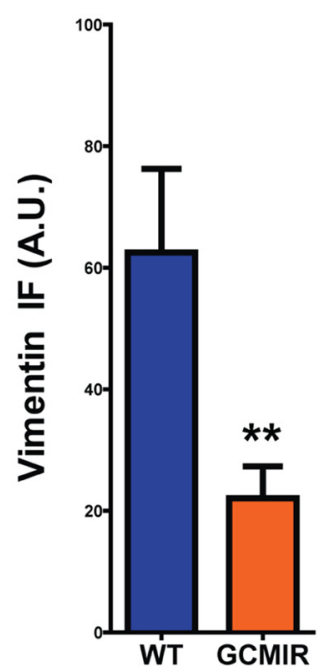

Figure 6. miR-21 reduces GFAP immunofluorescence in injured spinal cords at a chronic stage. WT and GCMIR spinal cords were analyzed 35 DPI after injury. $A$, Astrocytes expressed less GFAP (red) in GCMIR mice compared with WT around lesion, but still maintained compaction of activated microglia (Galectin 3, green). Scale bar, $100 \mu \mathrm{m}$. B, Magnified images (Figure legend continues.) 
the injured spinal cord, these observations supported a potentially important role for the miRNA in astrocytic responses to injury. To understand the functional significance of miR-21 in the astrocytic response, we therefore generated transgenic mice with altered levels of miR-21 specifically in astrocytes.

The GCMIR mouse conditionally overexpresses primary murine miR-21 from the ROSA26 locus under control of the GFAP promoter. We included portions of the primary sequence in our transgenic mouse line because BMP signaling, which is prominent after SCI, affects miR-21 processing and we wanted to preserve that biological phenomenon in our system (Davis et al., 2008; Sahni et al., 2010). We found that overexpression of miR-21 in astrocytes abrogated the hypertrophic response that is initially seen after severe SCI (Barnabé-Heider and Frisén, 2008). Astrocytes in these animals did not exhibit the normal increase in soma size or process thickness, nor did they display the normal increase in expression levels of reactive markers such as GFAP and vimentin. This effect of miR-21 was consistent with our previous report that overexpression of miR-21 in cultured astrocytes reduced cell size, process thickness, and GFAP expression (Sahni et al., 2010). Interestingly, a similar effect on cell morphology has been reported in cardiomyocytes, where they develop fine processes when miR-21 is overexpressed (Sayed et al., 2008), suggesting a conserved role for miR-21. Hypertrophic reactive astrocytes help repair the blood-brain barrier and limit infiltration of inflammatory cells into the parenchyma, thereby limiting the extent of damage. Consequently, the lesion size was increased in the GCMIR mice 2 weeks after injury. These findings indicate that expression of miR-21 attenuates the hypertrophic reactive response of astrocytes to injury.

To more clearly define the physiological role of endogenous miR-21 in the astrocytic response, we generated transgenic mice that use miRNA sponge technology to inhibit miR-21 function. miRNA sponges act as competitive inhibitors for miRNAs as the sponge transcript is expressed at higher levels and contains more binding sites than the typical target mRNA (Ebert et al., 2007). This type of miRNA inhibition has been used successfully in vitro as well as in vivo to study the function of other miRNAs (Valastyan et al., 2009; Ma et al., 2010; Dey et al., 2011; Luikart et al., 2011; Åkerblom et al., 2012), although to the best of our knowledge, we have generated the first transgenic mouse that utilizes miRNA sponge technology to inhibit miR-21 function. Astrocytic hypertrophy after SCI was enhanced in GCMSP-injured spinal cords not only during the early phases of the glial injury response when hypertrophy normally occurs, but even at later stages when astrocytes are typically smaller with finer processes. We also detected almost a twofold increase in axon density (SMI$312+$ ) through the lesion core in GCMSP cords. Since the transgene was expressed only in astrocytes, the changes in axon density were non-cell autonomous effects on neurons indicating that inhibiting miR-21 function in astrocytes creates a lesion environment that is more conducive for axons. It is unclear whether this is due to enhanced sparing of axons, increased axonal growth into the injury site, or both. Regardless, these findings suggest that regulation of miR-21 function in astrocytes influences axonal responses to SCI.

\section{$\leftarrow$}

(Figure legend continued.) (from $\boldsymbol{A}$ ) showed equal numbers of astrocytes but reduced GFAP staining (red) in GCMIR. Scale bar, $25 \mu \mathrm{m}$. C, GFAP immunofluorescence is reduced with 200 $\mu \mathrm{m}$ of lesion in GCMIR mice. D, GFAP (red) and vimentin (green) is reduced in GCMIR astrocytes adjacent to lesion. $\boldsymbol{E}$, GCMIR astrocytes showed reduced vimentin immunofluorescence. $n=$ $3-5$ mice, ${ }^{* *} p<0.01$ by Student's $t$ test. Dashed white lines indicate lesion edge.
miRNAs function by inhibiting translation of target mRNAs. Target prediction algorithms such as TargetScan and PicTar identify numerous genes that could potentially serve as mediators of miR-21 function, such as programmed cell death protein 4 (PDCD4) and phosphatase and tensin homolog (PTEN). However, we could not detect significant changes in PTEN protein levels when miR-21 function was modulated in astrocytes, nor did we see changes in levels of PDCD4 (data not shown). It is therefore likely that miR-21 functions in astrocytes to control a distinct set of yet unidentified gene targets, which in turn regulate astrocytic size and glial scar formation after SCI. The GCMIR and GCMSP mice developed in this study can potentially be used to discern such genes to identify novel targets for therapeutics.

Although this study did not define the signaling molecules that activate the miR-21 response to injury, prior work suggests that BMP signaling may be important. BMP signaling increases levels of miR-21 in vascular smooth muscle cells by regulating processing into the mature form, analogous to the findings of this study as levels of BMP4 and of BMP receptors increase in response to SCI (Setoguchi et al., 2001; Chen et al., 2005; Sahni et al., 2010). Further, we recently reported that BMP receptors Ia (BMPRIa) and Ib (BMPRIb) modulate miR-21 levels differently in cultured astrocytes; BMPRIb signaling increases miR-21 while BMPRIa signaling counters the increase (Sahni et al., 2010). We also found that BMPRIa ablation in astrocytes causes deficits in astrocytic hypertrophy and consequently results in increased lesion size after SCI, similar to what we found here in the GCMIR mice. Conversely, BMPRIb ablation enhances glial scar progression after SCI, similar to what is seen in the GCMSP injured spinal cords. Thus, it is plausible that BMPRIa signaling enhances astrocytic hypertrophy by limiting miR-21 expression while BMPRIb signaling inhibits it by increasing miR-21. JAK-STAT signaling is also activated after SCI, and the miR-21 regulatory sequence contains a highly conserved 300 base pair region consisting of two STAT3-binding sites (Löffler et al., 2007). JAKSTAT signaling is thus an activator of pri-miR-21 transcription. But STAT3 ablation in astrocytes limited the early astrocytic hypertrophy after SCI and increased invasion of inflammatory cells within the lesion (Herrmann et al., 2008), which would not be the predicted response. However, it is not clear whether JAK-STAT signaling increases levels of mature miR-21 after SCI, and the balance between BMP and JAK-STAT in injured spinal cord astrocytes is also unclear. The availability of the GCMIR and GCMSP mice should help to define the relationship after SCI between miR-21 and these signaling pathways.

This study was a short (five week) study designed to examine the effects of miR-21 in acute and chronic stages of astrogliosis. It would be unlikely to have functional regeneration or significant improvement in motor function in such a timeframe. Further, it is unlikely that this single molecular intervention will be sufficient to lead to significant enhancement in function. However, future studies that combine regulation of miR-21 function with other interventions that address additional aspects of the cellular changes after SCI offer a promising new approach to treatment of SCI.

In summary, we have found that levels of mature miR-21 increase in astrocytes in response to SCI and that the increase is maximal during the later phase of astrogliosis. miR-21 overexpression in astrocytes attenuates the beneficial hypertrophic response, whereas inhibiting the miRNA augments it, suggesting that it has a significant role in regulating astrocytic hypertrophy and glial scar progression. Moreover, inhibition of miR-21 function in astrocytes has the additional beneficial effect of increasing 
A
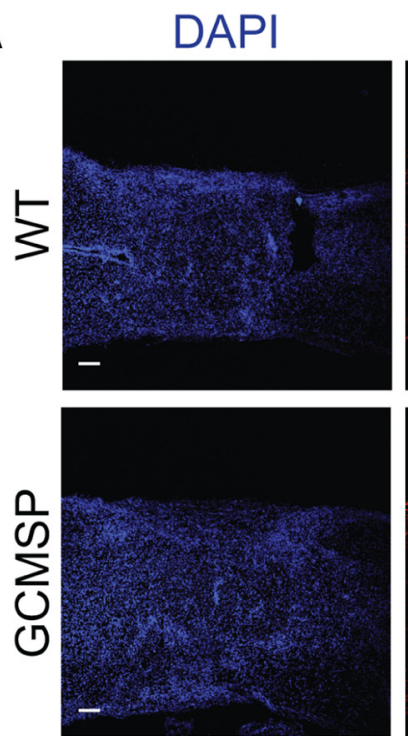

B
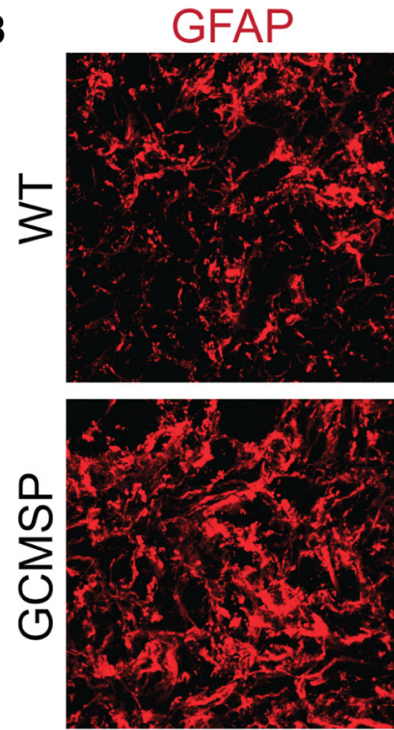

D
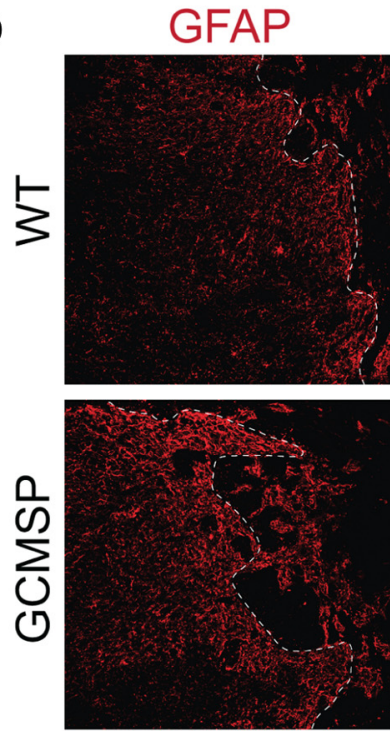

GFAP
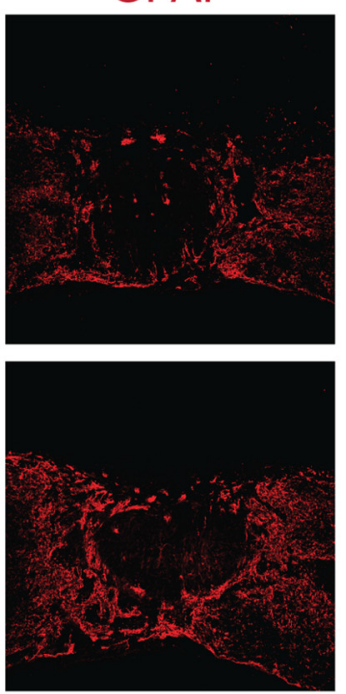

GFAP DAPI
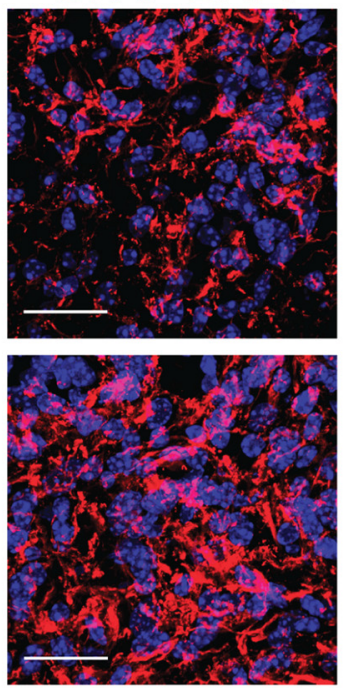

Vimentin
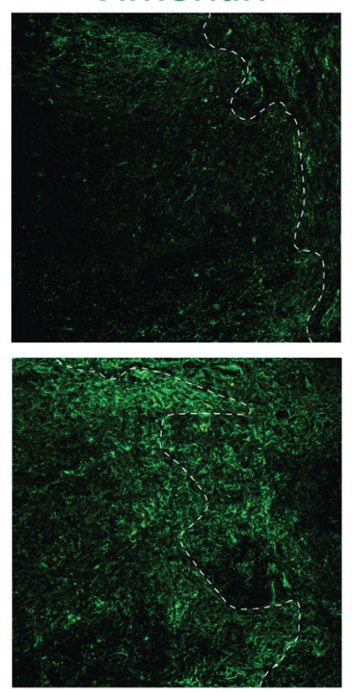

Galectin 3
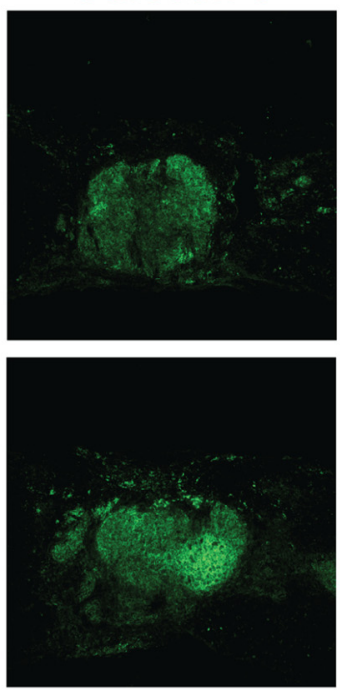

C

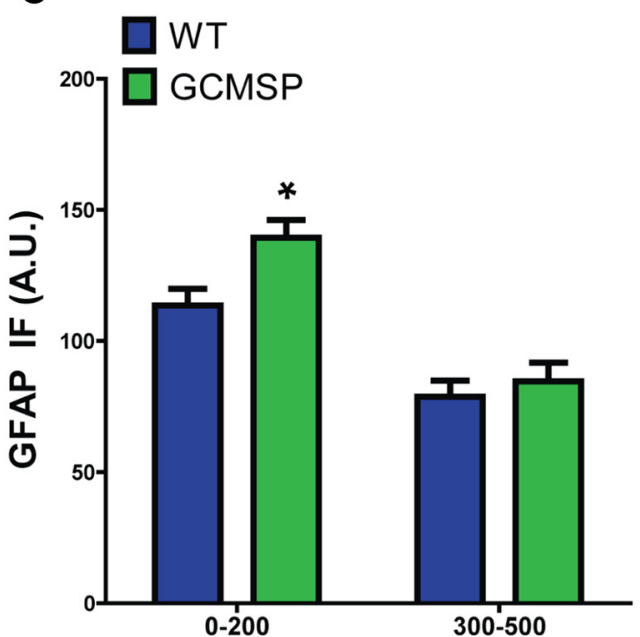

Distance from lesion edge (um)

Composite
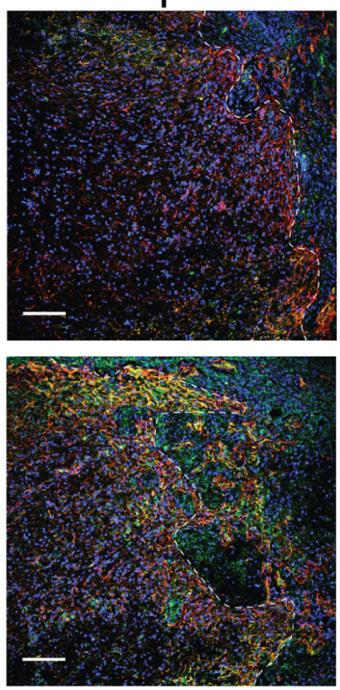

Composite
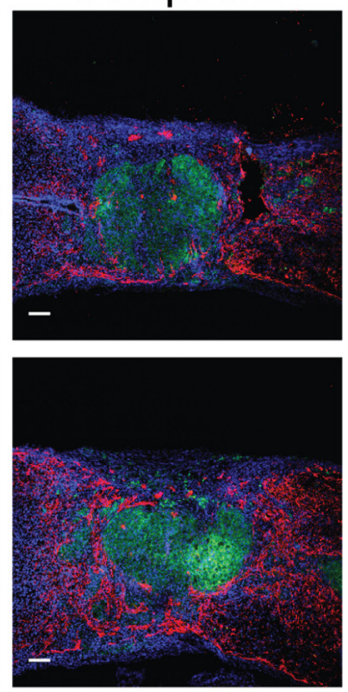

$-$

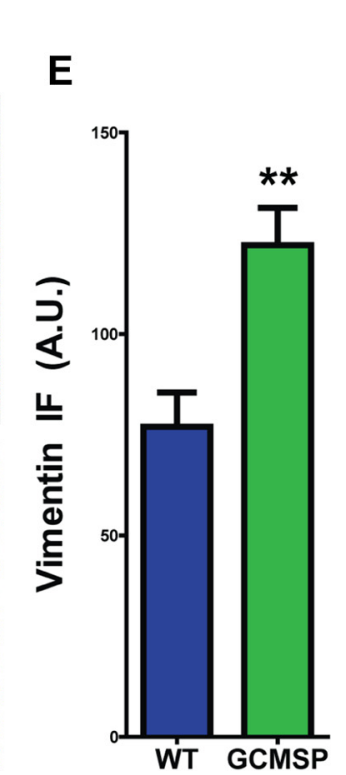

Figure 7. Astrocytic hypertrophy is maintained at chronic stages of injury in GCMSP mice. WT and GCMSP spinal cords were analyzed 35 DPI after injury. A, Astrocytes had more GFAP staining (red) and remained hypertrophic in GCMSP mice, compared with finely processed astrocytes seen in WT cords. Scale bar, $100 \mu \mathrm{m}$. B, High magnification shows increased GFAP (Figure legend continues.) 

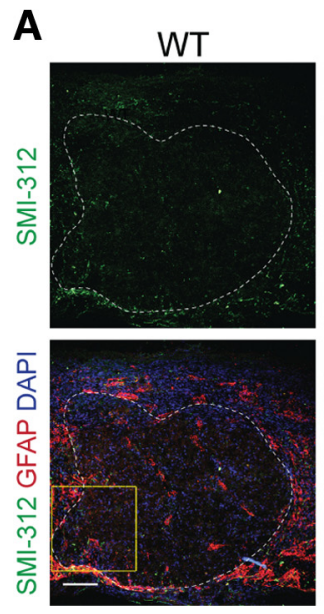

B
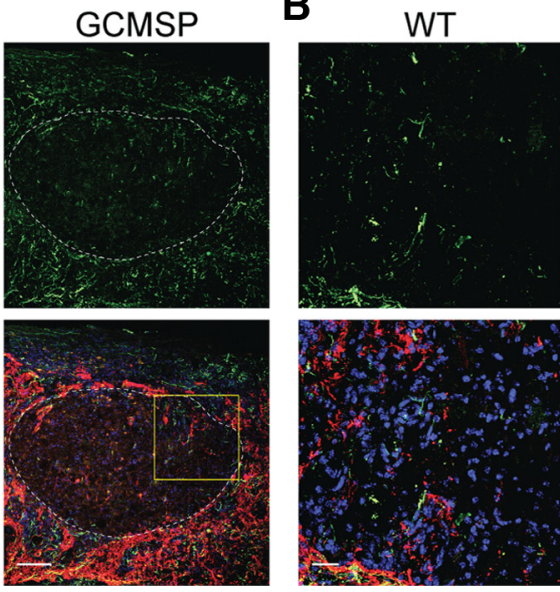
GCMSP
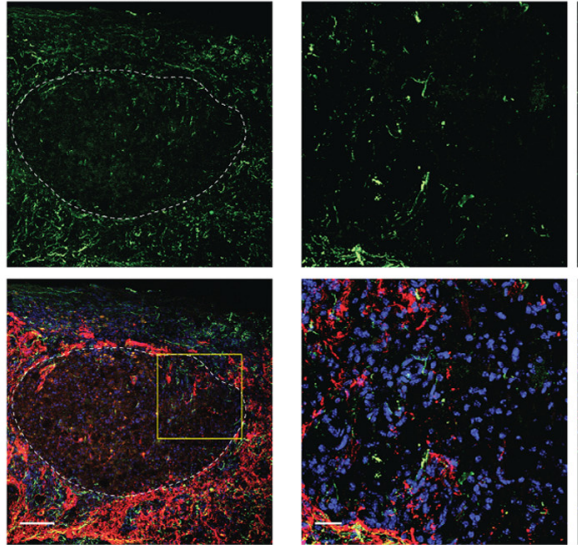
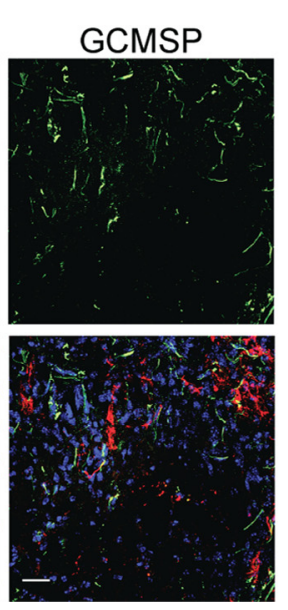

C

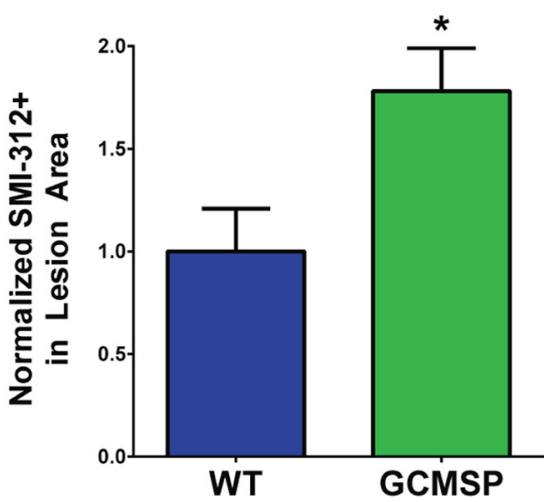

Figure 8. Inhibition of miR-21 increases axonal neurofilament expression through the lesion site. $\boldsymbol{A}$, Staining for the pan-axonal neurofilament marker SMI-312 (green) was increased within the lesion site, demarcated by the astrocytic GFAP border (dashed white line), in GCMSP mice compared with WT mice 35 DPI after injury. Scale bar, $100 \mu$ m. $\boldsymbol{B}$, Higher magnification (yellow boxes demarcated in $A$ ) of SMI-312 staining. Scale bar, $25 \mu \mathrm{m}$. C, Quantification of percentage of lesion area that is SMI-312+ demonstrated nearly a twofold increase in GCMSP mice normalized to WT. $n=3-6$ mice, ${ }^{*} p<0.05$ by Student's $t$ test.

axonal density through the glial scar. These findings suggest miR-21 as a potential molecular target for manipulating gliosis and enhancing functional outcome after SCI.

\section{References}

Ahmed MI, Mardaryev AN, Lewis CJ, Sharov AA, Botchkareva NV (2011) MicroRNA-21 is an important downstream component of BMP signalling in epidermal keratinocytes. J Cell Sci 124:3399-3404. CrossRef Medline

Åkerblom M, Sachdeva R, Barde I, Verp S, Gentner B, Trono D, Jakobsson J (2012) MicroRNA-124 is a subventricular zone neuronal fate determinant. J Neurosci 32:8879-8889. CrossRef Medline

Barnabé-Heider F, Frisén J (2008) Stem cells for spinal cord repair. Cell stem cell 3:16-24. CrossRef Medline

Barnabé-Heider F, Göritz C, Sabelström H, Takebayashi H, Pfrieger FW, Meletis K, Frisén J (2010) Origin of new glial cells in intact and injured adult spinal cord. Cell stem cell 7:470-482. CrossRef Medline

Bartel DP (2004) MicroRNAs: genomics, biogenesis, mechanism, and function. Cell 116:281-297. CrossRef Medline

Byrnes KR, Stoica B, Riccio A, Pajoohesh-Ganji A, Loane DJ, Faden AI (2009) Activation of metabotropic glutamate receptor 5 improves recovery after spinal cord injury in rodents. Ann Neurol 66:63-74. CrossRef Medline

Byrnes KR, Washington PM, Knoblach SM, Hoffman E, Faden AI (2011) Delayed inflammatory mRNA and protein expression after spinal cord injury. J Neuroinflammation 8:130. CrossRef Medline

Carthew RW, Sontheimer EJ (2009) Origins and mechanisms of miRNAs and siRNAs. Cell 136:642-655. CrossRef Medline

Chen J, Leong SY, Schachner M (2005) Differential expression of cell fate determinants in neurons and glial cells of adult mouse spinal cord after compression injury. Eur J Neurosci 22:1895-1906. CrossRef Medline

Davis BN, Hilyard AC, Lagna G, Hata A (2008) SMAD proteins control DROSHA-mediated microRNA maturation. Nature 454:56-61. CrossRef Medline

Dey N, Das F, Mariappan MM, Mandal CC, Ghosh-Choudhury N, Kasinath BS, Choudhury GG (2011) MicroRNA-21 orchestrates high glucose-

(Figure legend continued.) immunofluorescence (red) and hypertrophy in astrocytes around lesion site in GCMSP cords. Scale bar, $25 \mu \mathrm{m}$. C, Quantified GFAP immunofluorescence is increased $0-200 \mu \mathrm{m}$ from injury edge in GCMSP, but is unchanged $300-500 \mu \mathrm{m}$. D, Vimentin immunofluorescence (green) is greatly increased adjacent to lesion in GCMSP, indicating sustained reactive astrocytes. Scale bar, $100 \mu \mathrm{m}$. $\boldsymbol{E}$, Quantified vimentin immunofluorescence is increased in GCMSP injured cords $0-200 \mu \mathrm{m}$ from lesion edge. $n=3-6$ mice, ${ }^{*} p<0.05$, ${ }^{* *} p<0.01$. Dashed white lines indicate lesion edge. induced signals to TOR complex 1, resulting in renal cell pathology in diabetes. J Biol Chem 286:25586-25603. CrossRef Medline

Ebert MS, Neilson JR, Sharp PA (2007) MicroRNA sponges: competitive inhibitors of small RNAs in mammalian cells. Nat Methods 4:721-726. CrossRef Medline

Engesser-Cesar C, Anderson AJ, Basso DM, Edgerton VR, Cotman CW (2005) Voluntary wheel running improves recovery from a moderate spinal cord injury. J Neurotrauma 22:157-171. CrossRef Medline

Enzmann GU, Benton RL, Woock JP, Howard RM, Tsoulfas P, Whittemore SR (2005) Consequences of noggin expression by neural stem, glial, and neuronal precursor cells engrafted into the injured spinal cord. Exp Neurol 195:293-304. CrossRef Medline

Faulkner JR, Herrmann JE, Woo MJ, Tansey KE, Doan NB, Sofroniew MV (2004) Reactive astrocytes protect tissue and preserve function after spinal cord injury. J Neurosci 24:2143-2155. CrossRef Medline

Fawcett JW, Asher RA (1999) The glial scar and central nervous system repair. Brain Res Bull 49:377-391. CrossRef Medline

Garcia AD, Doan NB, Imura T, Bush TG, Sofroniew MV (2004) GFAPexpressing progenitors are the principal source of constitutive neurogenesis in adult mouse forebrain. Nat Neurosci 7:1233-1241. CrossRef Medline

Grider MH, Chen Q, Shine HD (2006) Semi-automated quantification of axonal densities in labeled CNS tissue. J Neurosci Methods 155:172-179. CrossRef Medline

Herrmann JE, Imura T, Song B, Qi J, Ao Y, Nguyen TK, Korsak RA, Takeda K, Akira S, Sofroniew MV (2008) STAT3 is a critical regulator of astrogliosis and scar formation after spinal cord injury. J Neurosci 28:7231-7243. CrossRef Medline

Kohanbash G, Okada H (2012) MicroRNAs and STAT interplay. Semin Cancer Biol 22:70-75. CrossRef Medline

Krichevsky AM, Gabriely G (2009) miR-21: a small multi-faceted RNA. J Cell Mol Med 13:39-53. Medline

Liu G, Keeler BE, Zhukareva V, Houl é JD (2010) Cycling exercise affects the expression of apoptosis-associated microRNAs after spinal cord injury in rats. Exp Neurol 226:200-206. CrossRef Medline

Liu G, Detloff MR, Miller KN, Santi L, Houl é JD (2012) Exercise modulates microRNAs that affect the PTEN/mTOR pathway in rats after spinal cord injury. Exp Neurol 233:447-456. CrossRef Medline

Liu NK, Wang XF, Lu QB, Xu XM (2009) Altered microRNA expression following traumatic spinal cord injury. Exp Neurol 219:424-429. CrossRef Medline

Löffler D, Brocke-Heidrich K, Pfeifer G, Stocsits C, Hackermüller J, Kretzschmar AK, Burger R, Gramatzki M, Blumert C, Bauer K, Cvijic H, Ullmann AK, Stadler PF, Horn F (2007) Interleukin-6 dependent survival of multiple myeloma cells involves the Stat3-mediated induction of microRNA-21 through a highly conserved enhancer. Blood 110:13301333. CrossRef Medline 
Luikart BW, Bensen AL, Washburn EK, Perederiy JV, Su KG, Li Y, Kernie SG, Parada LF, Westbrook GL (2011) miR-132 mediates the integration of newborn neurons into the adult dentate gyrus. PloS One 6:e19077. CrossRef Medline

Ma F, Xu S, Liu X, Zhang Q, Xu X, Liu M, Hua M, Li N, Yao H, Cao X (2011) The microRNA miR-29 controls innate and adaptive immune responses to intracellular bacterial infection by targeting interferon-gamma. Nat Immunol 12:861-869. CrossRef Medline

Ma L, Young J, Prabhala H, Pan E, Mestdagh P, Muth D, Teruya-Feldstein J, Reinhardt F, Onder TT, Valastyan S, Westermann F, Speleman F, Vandesompele J, Weinberg RA (2010) miR-9, a MYC/MYCN-activated microRNA, regulates E-cadherin and cancer metastasis. Nat Cell Biol 12: 247-256. Medline

Madathil SK, Nelson PT, Saatman KE, Wilfred BR (2011) MicroRNAs in CNS injury: potential roles and therapeutic implications. BioEssays 33: 21-26. CrossRef Medline

Masliah E, Mallory M, Hansen L, Alford M, DeTeresa R, Terry R (1993) An antibody against phosphorylated neurofilaments identifies a subset of damaged association axons in Alzheimer's disease. Am J Pathol 142:871882. Medline

Matsuura I, Taniguchi J, Hata K, Saeki N, Yamashita T (2008) BMP inhibition enhances axonal growth and functional recovery after spinal cord injury. J Neurochem 105:1471-1479. CrossRef Medline

Moriyama T, Ohuchida K, Mizumoto K, Yu J, Sato N, Nabae T, Takahata S, Toma H, Nagai E, Tanaka M (2009) MicroRNA-21 modulates biological functions of pancreatic cancer cells including their proliferation, invasion, and chemoresistance. Mol cancer Ther 8:1067-1074. CrossRef Medline

Newman MA, Hammond SM (2010) Emerging paradigms of regulated microRNA processing. Genes Dev 24:1086-1092. CrossRef Medline

Obernosterer G, Martinez J, Alenius M (2007) Locked nucleic acid-based in situ detection of microRNAs in mouse tissue sections. Nat Protoc 2:15081514. CrossRef Medline

Okada S, Nakamura M, Katoh H, Miyao T, Shimazaki T, Ishii K, Yamane J, Yoshimura A, Iwamoto Y, Toyama Y, Okano H (2006) Conditional ablation of Stat 3 or Socs 3 discloses a dual role for reactive astrocytes after spinal cord injury. Nat Med 12:829-834. CrossRef Medline

Pekny M, Pekna M (2004) Astrocyte intermediate filaments in CNS pathologies and regeneration. J Pathol 204:428-437. CrossRef Medline

Qureshi IA, Mehler MF (2012) Emerging roles of non-coding RNAs in brain evolution, development, plasticity and disease. Nat Rev Neurosci 13:528-541. CrossRef

Sahni V, Mukhopadhyay A, Tysseling V, Hebert A, Birch D, Mcguire TL, Stupp SI, Kessler JA (2010) BMPR1a and BMPR1b signaling exert opposing effects on gliosis after spinal cord injury. J Neurosci 30:1839-1855. CrossRef

Sayed D, Rane S, Lypowy J, He M, Chen IY, Vashistha H, Yan L, Malhotra A, Vatner D, Abdellatif M (2008) MicroRNA-21 targets Sprouty2 and pro- motes cellular outgrowths. Mol Biol Cell 19:3272-3282. CrossRef Medline

Schaft J, Ashery-Padan R, van der Hoeven F, Gruss P, Stewart AF (2001) Efficient FLP recombination in mouse ES cells and oocytes. Genesis 31: 6-10. CrossRef Medline

Scheff SW, Rabchevsky AG, Fugaccia I, Main JA, Lumpp JE Jr (2003) Experimental modeling of spinal cord injury: characterization of a forcedefined injury device. J Neurotrauma 20:179-193. CrossRef Medline

Setoguchi T, Yone K, Matsuoka E, Takenouchi H, Nakashima K, Sakou T, Komiya S, Izumo S (2001) Traumatic injury-induced BMP7 expression in the adult rat spinal cord. Brain Res 921:219-225. CrossRef Medline

Setoguchi T, Nakashima K, Takizawa T, Yanagisawa M, Ochiai W, Okabe M, Yone K, Komiya S, Taga T (2004) Treatment of spinal cord injury by transplantation of fetal neural precursor cells engineered to express BMP inhibitor. Exp Neurol 189:33-44. CrossRef Medline

Si ML, Zhu S, Wu H, Lu Z, Wu F, Mo YY (2007) miR-21-mediated tumor growth. Oncogene 26:2799-2803. CrossRef Medline

Silver J, Miller JH (2004) Regeneration beyond the glial scar. Nat Rev Neurosci 5:146-156. CrossRef Medline

Sofroniew MV (2005) Reactive astrocytes in neural repair and protection. Neuroscientist 11:400-407. CrossRef Medline

Srinivas S, Watanabe T, Lin CS, William CM, Tanabe Y, Jessell TM, Costantini F (2001) Cre reporter strains produced by targeted insertion of EYFP and ECFP into the ROSA26 locus. BMC Dev Biol 1:4. CrossRef Medline

Strickland ER, Hook MA, Balaraman S, Huie JR, Grau JW, Miranda RC (2011) MicroRNA dysregulation following spinal cord contusion: implications for neural plasticity and repair. Neuroscience 186:146-160. CrossRef Medline

Ulfig N, Nickel J, Bohl J (1998) Monoclonal antibodies SMI 311 and SMI 312 as tools to investigate the maturation of nerve cells and axonal patterns in human fetal brain. Cell Tissue Res 291:433-443. CrossRef Medline

Valastyan S, Reinhardt F, Benaich N, Calogrias D, Szász AM, Wang ZC, Brock JE, Richardson AL, Weinberg RA (2009) A pleiotropically acting microRNA, miR-31, inhibits breast cancer metastasis. Cell 137: 1032-1046. CrossRef Medline

Wang P, Zou F, Zhang X, Li H, Dulak A, Tomko RJ Jr, Lazo JS, Wang Z, Zhang L, Yu J (2009) microRNA-21 negatively regulates Cdc25A and cell cycle progression in colon cancer cells. Cancer Res 69:8157-8165. CrossRef Medline

Yunta M, Nieto-Díaz M, Esteban FJ, Caballero-López M, Navarro-Ruíz R, Reigada D, Pita-Thomas DW, del Águila A, Muñoz-Galdeano T, Maza RM (2012) MicroRNA dysregulation in the spinal cord following traumatic injury. PloS one 7:e34534. CrossRef Medline

Ziu M, Fletcher L, Rana S, Jimenez DF, Digicaylioglu M (2011) Temporal differences in microRNA expression patterns in astrocytes and neurons after ischemic injury. PloS one 6:e14724. CrossRef Medline 